\title{
Mainz Isoprene Mechanism 2 (MIM2): an isoprene oxidation mechanism for regional and global atmospheric modelling
}

\author{
D. Taraborrelli, M. G. Lawrence, T. M. Butler, R. Sander, and J. Lelieveld \\ Max Planck Institute for Chemistry, Atmospheric Chemistry Department, P.O. Box 3060, 55020 Mainz, Germany
}

Received: 26 May 2008 - Published in Atmos. Chem. Phys. Discuss.: 23 July 2008

Revised: 9 April 2009 - Accepted: 9 April 2009 - Published: 27 April 2009

\begin{abstract}
We present an oxidation mechanism of intermediate size for isoprene (2-methyl-1,3-butadiene) suitable for simulations in regional and global atmospheric chemistry models, which we call MIM2. It is a reduction of the corresponding detailed mechanism in the Master Chemical Mechanism (MCM v3.1) and intended as the second version of the well-established Mainz Isoprene Mechanism (MIM). Our aim is to improve the representation of tropospheric chemistry in regional and global models under all $\mathrm{NO}_{\mathrm{x}}$ regimes. We evaluate MIM2 and re-evaluate MIM through comparisons with MCM v3.1. We find that MIM and MIM2 compute similar $\mathrm{O}_{3}, \mathrm{OH}$ and isoprene mixing ratios. Unlike MIM, MIM2 produces small relative biases for $\mathrm{NO}_{\mathrm{x}}$ and organic nitrogen-containing species due to a good representation of the alkyl and peroxy acyl nitrates $\left(\mathrm{RONO}_{2}\right.$ and $\left.\mathrm{RC}(\mathrm{O}) \mathrm{OONO}_{2}\right)$. Moreover, MIM2 computes only small relative biases with respect to hydrogen peroxide $\left(\mathrm{H}_{2} \mathrm{O}_{2}\right)$, methyl peroxide $\left(\mathrm{CH}_{3} \mathrm{OOH}\right)$, methanol $\left(\mathrm{CH}_{3} \mathrm{OH}\right)$, formaldehyde (HCHO), peroxy acetyl nitrate (PAN), and formic and acetic acids ( $\mathrm{HCOOH}$ and $\left.\mathrm{CH}_{3} \mathrm{C}(\mathrm{O}) \mathrm{OH}\right)$, being always below $\approx 6 \%$ in all $\mathrm{NO}_{\mathrm{x}}$ scenarios studied. Most of the isoprene oxidation products are represented explicitly, including methyl vinyl ketone (MVK), methacrolein (MACR), hydroxyacetone and methyl glyoxal. MIM2 is mass-conserving with respect to carbon, including $\mathrm{CO}_{2}$ as well. Therefore, it is suitable for studies assessing carbon monoxide (CO) from biogenic sources, as well as for studies focused on the carbon cycle. Compared to MIM, MIM2 considers new species like acetaldehyde $\left(\mathrm{CH}_{3} \mathrm{CHO}\right)$, propene $\left(\mathrm{CH}_{2}=\mathrm{CHCH}_{3}\right)$ and glyoxal (CHOCHO) with global chemical production rates for the year 2005 of $7.3,9.5$ and $33.8 \mathrm{Tg} / \mathrm{yr}$, respectively. Our new mechanism is expected to substantially improve
\end{abstract}

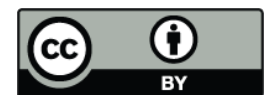

Correspondence to: D. Taraborrelli (tara@mpch-mainz.mpg.de) the results of atmospheric chemistry models by representing many more intermediates, that are transported and deposited, which allows us to test model results with many more new measurements. MIM2 allows regional and global models to easily incorporate new experimental results on the chemistry of organic species.

\section{Introduction}

Isoprene is the main biogenic volatile organic compound (VOC) emitted by vegetation and strongly affects the composition of the troposphere. Global emission estimates are in the range $410-600 \mathrm{Tg} / \mathrm{yr}(362-530 \mathrm{Tg}(\mathrm{C}) / \mathrm{yr})$ (Guenther et al., 1995, 2006; Lathière et al., 2006; Müller et al., 2008). The main oxidation pathways of isoprene are reactions with $\mathrm{OH}, \mathrm{O}_{3}$ and $\mathrm{NO}_{3}$, with the OH-pathway being by far the most important. This is due to the high reaction rate with $\mathrm{OH}$ and to the coincidence of the strong light- and temperaturedependent emissions (Fehsenfeld et al., 1992; Yokouchi, 1994) with the peak in $\mathrm{OH}$ concentrations during the day. Many experimental studies have been conducted so far, and product yields for many species, with and without $\mathrm{NO}_{\mathrm{x}}$, have been determined. For instance, the $\mathrm{OH}$-pathway has been investigated extensively in a number of studies (Tuazon and Atkinson, 1990; Paulson et al., 1992a; Miyoshi et al., 1994; Kwok et al., 1995; Benkelberg et al., 2000; Ruppert and Becker, 2000; Sprengnether et al., 2002; Lee et al., 2005; Paulot et al., 2009). Fewer studies on the stable products from the $\mathrm{O}_{3}$-pathway have been performed (Paulson et al., 1992b; Grosjean et al., 1993; Aschmann and Atkinson, 1994; Atkinson et al., 1994; Sauer et al., 1999), while a number of studies focused specifically on the OH-yields (Atkinson et al., 1992; Gutbrod et al., 1997; Paulson et al., 1998; Neeb and Moortgat, 1999; Rickard et al., 1999; Lewin et al.,

Published by Copernicus Publications on behalf of the European Geosciences Union. 
2001). On the other hand, chemical properties have been determined for a few oxidation products (Atkinson et al., 2006). A substantial fraction of the global isoprene production occurs in regions of the Southern Hemisphere where NO mixing ratios are below $60 \mathrm{pmol} / \mathrm{mol}$ (Müller et al., 2008; Torres and Buchan, 1988; Emmons et al., 1997). Under these conditions, after $\mathrm{HCHO}$, the hydroperoxides are the next most abundant products, with a maximum product yield ranging between 32 and 48\% (Benkelberg et al., 2000; Jenkin et al., 1997). Their chemical properties have not been measured yet, but they are predicted to be very reactive and critical to adequately represent the isoprene chemistry in low- $\mathrm{NO}_{\mathrm{x}}$ conditions. Other important products under all $\mathrm{NO}_{\mathrm{x}}$-regimes are methy vinyl ketone (MVK), methacrolein (MACR), $\mathrm{C}_{5}$-carbonyls, glycolaldehyde, glyoxal, hydroxyacetone and methylglyoxal. The knowledge of isoprene chemistry is still incomplete, many uncertainties remain, and only a few detailed isoprene mechanisms exist. Three of them are described in Fan and Zhang (2004), Madronich and Calvert (1989) and Carter and Atkinson (1996), with the last one being evaluated against a chamber study (Carter, 2000). Another detailed mechanism of isoprene oxidation is included in the Master Chemical Mechanism (MCM v3.1) (Jenkin et al., 1997; Saunders et al., 2003). It can be freely accessed at the website: http://mcm.leeds.ac.uk/MCM. This isoprene mechanism is highly explicit, providing a description of the complete degradation of isoprene and its degradation products, initiated (where appropriate) by reaction with $\mathrm{OH}, \mathrm{O}_{3}, \mathrm{NO}_{3}$ and photolysis. However, it already contains some level of reduction compared with the related subset mechanisms of Jenkin and Hayman (1995) and Jenkin et al. (1998), which treat the OH-initiated degradation to first generation products in greater detail. The reduction in the MCM of the more detailed chemistry consisted of neglecting the formation of two minor hydroxy peroxy radicals from the $\mathrm{OH}$-addition pathway, which together represent about $10 \%$ of the reaction products.

Recently, the MCM has been evaluated against $\mathrm{NO}_{\mathrm{x}}$-air chamber experiments (Pinho et al., 2005). Moreover, it has been applied in many recent field studies (Biesenthal et al., 1998; Warneke et al., 2001; Williams et al., 2001; Carslaw et al., 1999a, 2001; Kubistin et al., 2008). However, detailed mechanisms like the MCM are not suitable for global atmospheric chemistry simulations due to computational limitations, and a reduced mechanism must be employed. The mechanism reduction must be applied, although this is known to lead to loss of accuracy and information (Whitehouse et al., 2004a,b; Carslaw et al., 1999b, and references therein). Moreover, inaccuracies in the representation of important intermediate species adds further uncertainties to 3-D atmospheric models due to the interplay between chemistry, transport and deposition. Therefore, assessments of all these uncertainties in the models must be performed. In this work we re-evaluate the Mainz Isoprene Mechanism (MIM, Pöschl et al., 2000), which is an earlier reduction of
MCM. We present and evaluate a new reduced mechanism of intermediate size for isoprene, which we call MIM2. We show that, unlike MIM, MIM2 preserves the basic features of the corresponding detailed mechanism and shows similar nonlinear behaviour. A set of reduction principles that lead to its development is presented in Sect. 2. A box model evaluation of MIM2 and MIM against MCM for three $\mathrm{NO}_{\mathrm{x}}$ scenarios is presented in Sect. 3. Then, preliminary results from the implementation of MIM2 in the global atmospheric chemistry model ECHAM5/MESSy are presented in Sect. 4. Finally, in Sect. 6 the main features and advantages of MIM2 are summarized.

\section{From MCM to MIM2: mechanism reduction}

\subsection{Background}

The chemistry of terpenes (e.g. isoprene and monoterpenes) has a large range of oxidation reaction pathways and products (Atkinson and Arey, 2003a,b). To our knowledge, all VOC oxidation mechanisms employed in global atmospheric chemistry models neglect most of the products and isomers arising from terpene oxidation Horowitz et al. (2007); Houweling et al. (1998); Geiger et al. (2003); von Kuhlmann et al. (2004); Brasseur et al. (1998); Wang and Shallcross (2000); Folberth et al. (2006); Wang et al. (1998). Furthermore, mechanisms like MIM often include lumped species which represent many compounds, sometimes with very different chemical structures and properties. Thus, they fail to reproduce the nonlinear behaviours of its tropospheric chemistry under different conditions, e.g., differences in product yields in the absence and presence of $\mathrm{NO}_{\mathrm{x}}$ (Jenkin et al., 1998; Ruppert and Becker, 2000). For example, MIM considers only one product for each class of $\mathrm{C}_{5}-$ and $\mathrm{C}_{4}$-compounds: one carbonyl species instead of four isomers, two alkyl nitrates instead of eight compounds and one hydroperoxide instead of four isomers. It can only poorly reproduce the experimental results or the diurnal cycle of the total nitrates (see Sect. 3.6.1). MIM, as well as many other condensed mechanisms, has to be taken as an entity without changing individual rate constants or reaction products. For instance, while the average MCM alkyl nitrate yield is $10 \%$, in MIM a $4.4 \%$ yield based on an experimental study by Chen et al. (1998) was adopted and the results were tuned accordingly. Afterwards, von Kuhlmann et al. (2004) increased this yield in MIM to $12 \%$ following Sprengnether et al. (2002), which we have found leads to undesirable side effects on the results of the mechanism (see Sect. 3). Changing such yields in MIM was accepted only because of the large experimental uncertainties in the literature, with estimates ranging between 4.4 and 15\% (Chen et al., 1998; Sprengnether et al., 2002; Giacopelli et al., 2005; Patchen et al., 2007). However, we note that modifications of a highly-tuned reduced mechanism like MIM, or usage of any subset of its reactions, 
Table 1. Number of reactions and species for each mechanism.

\begin{tabular}{cccc}
\hline Mechanism & Stable species $^{\mathrm{a}}$ & Species $^{\mathrm{a}}$ & Reactions $^{\mathrm{b}}$ \\
\hline MCM & 150 & 180 & $583(+12)$ \\
MIM & 12 & 15 & $42(+2)$ \\
MIM2 & 53 & 68 & $195(+4)$ \\
\hline
\end{tabular}

a Note that only $\mathrm{C}_{2}-\mathrm{C}_{5}$ species have been taken into account.

$\mathrm{b}$ Inside the parentheses are the number of photolysis reactions of PAN-like compounds that must be included when modeling the upper troposphere.

can lead to serious misinterpretation of either field or experimental data. Nevertheless, to date there have been several applications of such modified version of MIM. There are two global atmospheric chemistry models, MATCH-MPIC (Lawrence et al., 2003; von Kuhlmann et al., 2003) and ECHAM5/MESSy (Jöckel et al., 2006; Pozzer et al., 2007) in which this modified MIM was included. Moreover, 19 out of the 44 reactions of MIM were used to update the isoprene mechanism of the well-established mechanism RACM (Stockwell et al., 1997) and were tested against a chamber study (EUPHORE) (Geiger et al., 2003). This mechanism was then used to analyse long-term measurements of atmospheric OH concentrations (Rohrer and Berresheim, 2006). After a slight modification, the mechanism was used to perform a product and a kinetic study of isoprene chemistry with the SAPHIRE chamber (Karl et al., 2006).

\subsection{Reduction principles}

Keeping in mind the background described above, the following principles for mechanism reduction have been conceived and adopted for designing MIM2:

1. Take the MCM for isoprene as the reference (Saunders et al., 2003, and references therein), with any errors or omissions it may contain.

2. Consider only $\mathrm{C}_{2}-\mathrm{C}_{5}$-species to be isoprene-related and hence belonging to the reduced mechanism.

3. Make the mechanism detailed enough to accurately reproduce the diurnal cycle of important intermediate species like carbonyls, hydroperoxides and alkyl and peroxy acyl nitrates. This is expected to be of relevance in order to properly simulate the atmospheric composition with 3-D models where transport and dry and wet deposition of species play a key role. MIM was intended to perform well in reproducing the concentrations of $\mathrm{O}_{3}, \mathrm{OH}, \mathrm{NO}_{\mathrm{x}}, \mathrm{H}_{2} \mathrm{O}_{2}, \mathrm{CH}_{3} \mathrm{OOH}, \mathrm{CO}$ and isoprene. While this generally works well, it will be shown in Sect. 3 that its biases with respect to MCM are sometimes significant even for these species.
Table 2. Initial mixing ratios of species under all $\mathrm{NO}_{\mathrm{x}}$ scenarios here presented

\begin{tabular}{|c|c|}
\hline Species formula & $\begin{array}{l}\text { initial mole fraction } \\
\qquad\left(\mathrm{mol} \mathrm{mol}^{-1}\right)\end{array}$ \\
\hline $\mathrm{H}_{2} \mathrm{O}$ & 0.01851 \\
\hline $\mathrm{O}_{3}$ & $30 \times 10^{-9}$ \\
\hline $\mathrm{H}_{2} \mathrm{O}_{2}$ & $7 \times 10^{-9}$ \\
\hline $\mathrm{NH}_{3}$ & $100 \times 10^{-12}$ \\
\hline $\mathrm{NO}_{2}$ & $100 \times 10^{-12}$ \\
\hline $\mathrm{NO}$ & $10 \times 10^{-12}$ \\
\hline HONO & $40 \times 10^{-14}$ \\
\hline $\mathrm{HNO}_{3}$ & $5.0 \times 10^{-12}$ \\
\hline $\mathrm{CH}_{4}$ & $1.8 \times 10^{-06}$ \\
\hline $\mathrm{HCHO}$ & $5.0 \times 10^{-09}$ \\
\hline $\mathrm{CO}$ & $100 \times 10^{-09}$ \\
\hline $\mathrm{CH}_{3} \mathrm{OH}$ & $500 \times 10^{-12}$ \\
\hline $\mathrm{CH}_{3} \mathrm{OOH}$ & $4.0 \times 10^{-09}$ \\
\hline $\mathrm{HCOOH}$ & $350 \times 10^{-12}$ \\
\hline $\mathrm{CH}_{3} \mathrm{C}(\mathrm{O}) \mathrm{O}_{2} \mathrm{NO}_{2}(\mathrm{PAN})$ & $100 \times 10^{-12}$ \\
\hline $\mathrm{CH}_{3} \mathrm{CO}_{2} \mathrm{H}$ & $2.0 \times 10^{-09}$ \\
\hline $\mathrm{CH}_{3} \mathrm{CO}_{3} \mathrm{H}$ & $1.5 \times 10^{-09}$ \\
\hline $\mathrm{CH}_{3} \mathrm{COCH}_{2} \mathrm{OH}$ & $4.0 \times 10^{-09}$ \\
\hline $\mathrm{CH}_{3} \mathrm{COCHO}$ & $500 \times 10^{-12}$ \\
\hline $\mathrm{C}_{5} \mathrm{H}_{8}$ (isoprene) & $2.0 \times 10^{-09}$ \\
\hline
\end{tabular}

4. Include any isoprene oxidation products which can be measured using modern instrumentation, and any other species which represent significant minor pathways but were neglected in previous mechanisms. Such species are glyoxal, glycolaldehyde, propene, acetaldehyde, $\alpha$ nitrooxy acetone, $\mathrm{C}_{5}$-hydroperoxides, diols, and $\mathrm{C}_{5^{-}}$ carbonyls. Recently, measurements of oxygenated organics during field campaigns and in laboratory experiments have become widespread Volkamer et al. (2005); Sinreich et al. (2007); Williams et al. (2001); de Gouw and Warneke (2007, and references therein). For glyoxal, a species absent in MIM, satellite retrievals have recently become possible and are becoming more reliable (Wittrock et al., 2006; Myriokefalitakis et al., 2008).

5. Neglect long-lived species only if they are formed in very small amounts $\left(<30 \mathrm{pmol} / \mathrm{mol}\right.$ under all $\mathrm{NO}_{\mathrm{x}}$ regimes studied). This principle ensures that their elimination from the mechanism does not significantly affect species like $\mathrm{O}_{3}$ and $\mathrm{OH}$. For instance this was the case for some peroxy acyl nitrates like the MCM species GLYPAN and C4PAN6.

6. Substitute all the species which react quickly at frequencies greater than $1 \mathrm{~s}^{-1}$ with the respective products of the major loss pathway. The species satisfying such 
principle are the Criegee biradicals (see Sect. 2.5) and alkoxy radicals with typical lifetimes being less than $1 \mathrm{~s}$. Whitehouse et al. (2004a) successfully applied a similar principle for all species that are set to decompose at a rate of $10^{6} \mathrm{~s}^{-1}$ in MCM. This was based on the idea that the long term behaviour of a chemical mechanism can be accurately represented by assuming that the faster time-scales equilibrate with respect to the slower ones.

7. Lump species that are always in a nearly constant ratio and have very similar reactivities. Species that react through the same paths, in reactions with same rate coefficients, can be lumped together without any loss of accuracy to the mechanism (Whitehouse et al., 2004b). Moreover, the loss of accuracy is small when species with very similar reactivities are lumped together. Hence, in this study, every lumped species is assumed to have reactivities and products equal to the corresponding weighted averages of the respective components. For an example see Sect. 2.4.

8. Adopt the MCM nomenclature and give lumped species a name starting with $L$ and being as similar as possible to the MCM names of the species it represents.

Designing MIM2 with such principles in mind has led to a mechanism that allows further mechanism development building directly on MIM2, which is not possible with MIM or most other contemporary reduced mechanisms. It is thus straightforward to test the effects of any new laboratory kinetic developments in atmospheric chemistry models using MIM2. Moreover, the fairly large number of $\mathrm{C}_{2}-\mathrm{C}_{5}$-species included in MIM2 allows global models like ECHAM5/MESSy (Jöckel et al., 2006) to include rather detailed organic aqueous-phase chemistry, which appears to be potentially important by often acting as a strong sink for trace gases like glyoxal (Volkamer et al., 2007; Loeffler et al., 2006; Hastings et al., 2005; Carlton et al., 2007) and MVK and MACR (Chen et al., 2008), and which may also be have implications for cloud microphysics (Nenes et al., 2002).

\subsection{The whole mechanism}

The size of MIM2 with respect to MCM and MIM is presented in Table 1. MIM2 consists of 69 species, of which 53 are long-lived and hence need to be transported in atmospheric chemistry models (see Table 1 in the Supplementary Material http://www.atmos-chem-phys. net/9/2751/2009/acp-9-2751-2009-supplement.pdf). These species are involved in 178 reactions (see Table 3 in the Supplementary Material http://www.atmos-chem-phys.net/ 9/2751/2009/acp-9-2751-2009-supplement.pdf). When implemented in 3-D atmospheric chemistry models, photolysis reactions of the 4 peroxy acyl nitrates must be added. These photolysis reactions are not considered in MCM because it was designed to simulate the lower troposphere. However, the photolysis of peroxy acyl nitrates can become the dominant sink in the upper troposphere (Talukdar et al., 1995; Nizkorodov et al., 2005).

\subsection{The OH-pathway}

Under atmospheric conditions the $\mathrm{OH}$-addition pathway for isoprene oxidation is by far the most important. The MCM considers the production of only four isomers of peroxy radicals, $\mathrm{RO}_{2}$, which is a reduction of an even more detailed mechanism (Jenkin and Hayman, 1995; Jenkin et al., 1998) that takes into account six possible isomers. In Fig. 1 a flow diagram illustrating the OH-pathway is shown. MIM2, as well as MCM, implicitly assumes the $\mathrm{OH}$-addition to occur only at position 1 and 4 with branching ratios being 0.655 and 0.345 , respectively. The $\mathrm{O}_{2}$-addition to the resulting alkyl radicals is assumed to be instantaneous. MIM2 considers the production of three different kinds of peroxy radicals (RO2), namely LISOPACO2, ISOPBO2 and ISOPDO2. They react with $\mathrm{NO}, \mathrm{NO}_{3}, \mathrm{HO}_{2}$ and $\mathrm{RO}_{2}$ according to the MCM protocol (Jenkin et al., 1997; Saunders et al., 2003). Unlike MIM, MIM2 retains the permutation reaction formalism adopted in MCM and the production of diols from such reactions. It is a simplified parameterization in which each $\mathrm{RO}_{2}$ reacts with a pool of $\mathrm{R}^{\prime} \mathrm{O}_{2}$ at a pseudo-first-order rate (Madronich and Calvert, 1990). The average alkyl nitrate yield from $\mathrm{RO}_{2}+\mathrm{NO}$ reactions in MIM2 is $10 \%$, as in the MCM. The yields of single isomers depend on the structure and are quite uncertain, and MIM2 enables sensitivity studies changing such yields. The species represented by LISOPACO2, namely ISOPAO2 and ISOPCO2, are not produced in equal amounts in MCM v3.1, but simulation tests showed that the corresponding products are always in a ratio of about 1:1. Since these species have identical reactivity and structurally similar products, the products have been lumped in LISOPACOOH (a lump of ISOPAOOH and ISOPCOOH), LHC4ACCHO and LISOPACNO3. They are the only first generation products that are lumped, where the term first generation denotes the first long-lived species produced in the oxidation chain. In summary, the first generation products from the OH-pathway in MIM2 are:

- Hydroperoxides: LISOPACOOH, ISOPBOOH and ISOPDOOH

- Carbonyls: LHC4ACCHO, MVK, MVKOH, MACR and HCOC5

- Diols: ISOPAOH, ISOPBOH and ISOPDOH

- Alkyl nitrates: LISOPACNO3, ISOPBNO3 and ISOPDNO3 
Table 3. Diurnal averages for the 5 th day of simulation for the cumulative loss of isoprene and $\mathrm{RO}_{2}\left(\mathrm{CH}_{3} \mathrm{O}_{2}\right.$ included) and the relative differences between MCM and MIM2 for selected species.

\begin{tabular}{|c|c|c|c|}
\hline & low- $\left[\mathrm{NO}_{\mathrm{x}}\right]$ & $\operatorname{mid}-\left[\mathrm{NO}_{\mathrm{X}}\right]$ & high- $\left[\mathrm{NO}_{\mathrm{X}}\right]$ \\
\hline \multicolumn{4}{|l|}{ scenario parameters } \\
\hline NO emiss. $\left(\mathrm{cm}^{-2} \mathrm{~s}^{-1}\right)$ & $3.33 \times 10^{9}$ & $3.33 \times 10^{10}$ & $3.33 \times 10^{11}$ \\
\hline$\left[\mathrm{NO}_{\mathrm{x}}\right] \max (\mathrm{nmol} \mathrm{mol}-1)$ & 0.128 & 0.765 & 5.066 \\
\hline \multicolumn{4}{|l|}{ Isoprene losses (\%) } \\
\hline $\mathrm{L}_{\mathrm{OH}}$ & 67.86 & 72.63 & 79.50 \\
\hline $\mathrm{L}_{\mathrm{O}_{3}}$ & 31.26 & 19.26 & 8.091 \\
\hline \multicolumn{4}{|l|}{$\mathrm{RO}_{2}$ losses $(\%)$} \\
\hline $\mathrm{L}_{\mathrm{NO}}$ & 24.46 & 50.34 & 75.22 \\
\hline $\mathrm{L}_{\mathrm{HO}_{2}}$ & 50.51 & 35.97 & 16.78 \\
\hline $\mathrm{L}_{\mathrm{R}^{\prime} \mathrm{O}_{2}}$ & 25.02 & 13.42 & 3.660 \\
\hline $\begin{array}{l}\mathrm{L}_{\mathrm{NO}_{3}} \\
\text { average relative biases }\end{array}$ & $<0.01$ & 0.2678 & 4.338 \\
\hline \multicolumn{4}{|l|}{ 100*(MIM2-MCM)/MCM (\%) } \\
\hline $\mathrm{O}_{3}$ & 1.115 & 1.095 & -0.6258 \\
\hline $\mathrm{OH}$ & 1.388 & 1.834 & 4.400 \\
\hline $\mathrm{HO}_{2}$ & -0.9017 & -0.1166 & 4.482 \\
\hline $\mathrm{H}_{2} \mathrm{O}_{2}$ & -0.3620 & -0.3668 & 0.5766 \\
\hline NO & -0.4443 & -2.771 & $-150.1^{a}$ \\
\hline $\mathrm{NO}_{2}$ & 2.422 & 1.240 & 2.125 \\
\hline $\mathrm{HNO}_{3}$ & 1.561 & 3.338 & 0.3348 \\
\hline $\mathrm{CH} 3 \mathrm{OH}$ & 2.472 & 1.782 & 1.760 \\
\hline $\mathrm{CH} 3 \mathrm{OOH}$ & 1.525 & 1.079 & 2.140 \\
\hline $\mathrm{HCHO}$ & 0.07727 & -0.8609 & -0.8305 \\
\hline $\mathrm{CO}$ & -0.2780 & -0.3393 & -0.8868 \\
\hline $\mathrm{HCOOH}$ & -0.4829 & -1.368 & -1.665 \\
\hline СH3CHO & 2.377 & -4.131 & -5.217 \\
\hline $\mathrm{CH} 3 \mathrm{CO} 2 \mathrm{H}$ & 2.312 & 1.961 & 1.929 \\
\hline PAN & 5.574 & 3.436 & 2.890 \\
\hline HOCH2CHO & 8.901 & -1.681 & -2.993 \\
\hline GLYOX & -1.800 & -0.8294 & 11.49 \\
\hline C3H6 & -0.6624 & -2.563 & -0.8083 \\
\hline NOA & 1.073 & 2.015 & 2.600 \\
\hline ACETOL & -0.4158 & 0.4043 & 3.176 \\
\hline MGLYOX & 5.285 & 2.793 & 3.166 \\
\hline MPAN & 1.963 & 0.1996 & -0.1643 \\
\hline MVK & 0.1867 & -1.471 & -0.5412 \\
\hline MACR & -0.1962 & -1.506 & -1.714 \\
\hline ISOPBOH & 0.9588 & -0.3463 & -0.1618 \\
\hline ISOPBOOH & -0.7308 & -1.788 & -0.8294 \\
\hline ISOPBNO3 & 0.3808 & -1.932 & -2.417 \\
\hline ISOPDOH & 0.2964 & -0.1322 & -3.129 \\
\hline ISOPDOOH & -1.446 & -1.643 & -4.978 \\
\hline ISOPDNO3 & -0.1476 & -1.885 & -3.888 \\
\hline NC4CHO & 2.569 & -0.5616 & -2.098 \\
\hline $\mathrm{C} 5 \mathrm{H} 8$ & -1.137 & -4.022 & $62.40^{\mathrm{a}}$ \\
\hline
\end{tabular}

a The value has little significance as it was found to be result of very small absolute biases at night when the concentrations of the tracer are close to zero. 


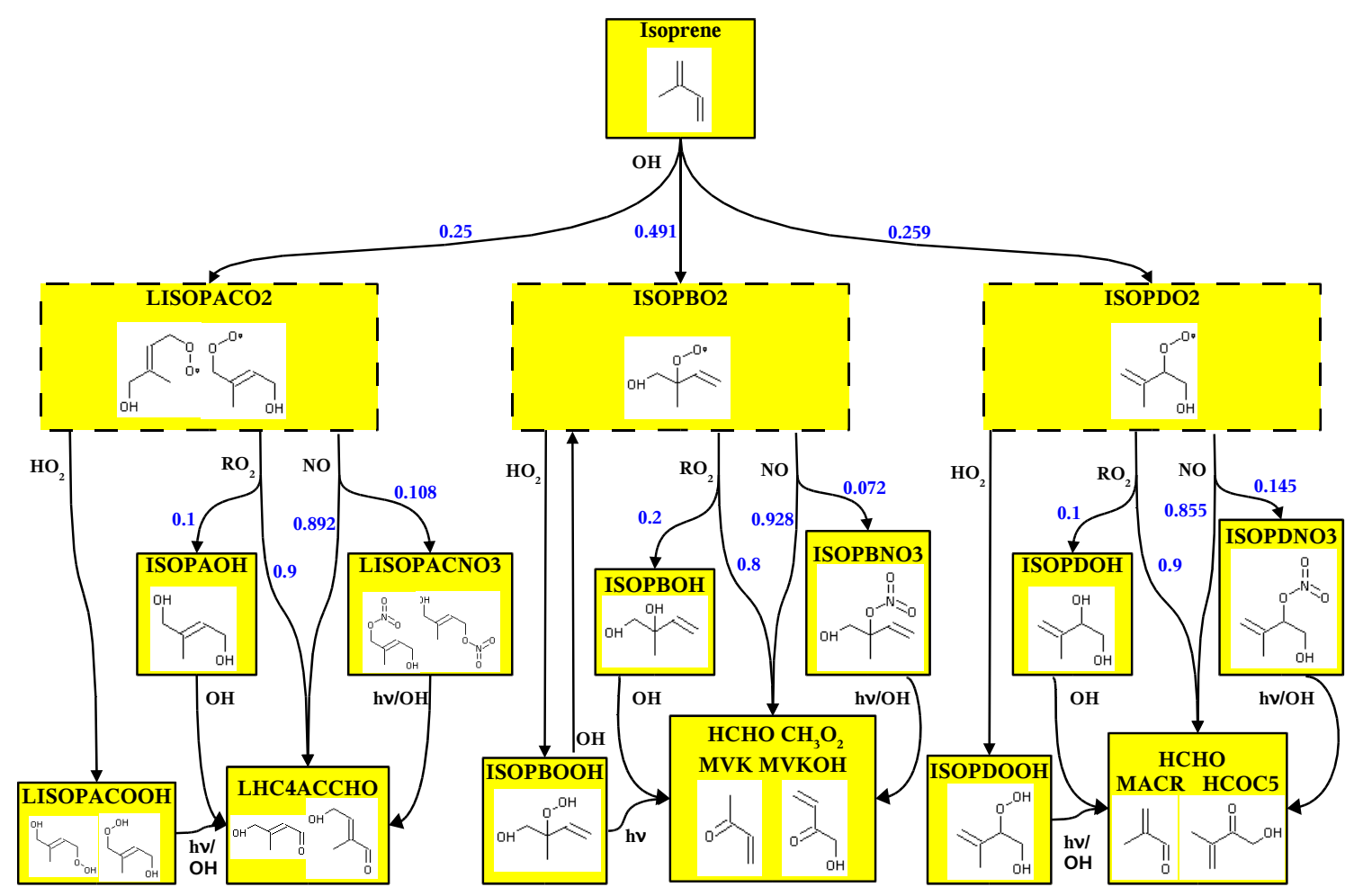

Fig. 1. The $\mathrm{OH}$-addition pathway in MIM2. The three short-lived peroxy radicals from isoprene are delimited by dashed lines. The branching ratios of each reaction are indicated in light blue.

\section{$2.5 O_{3}$-pathway}

The ozonolysis of alkenes generates carbonyls and energetic Criegee biradicals (Atkinson and Arey, 2003a). The fate of such biradicals is described in Jenkin et al. (1997) as being a relaxation process that can yield significant amounts of $\mathrm{OH}$. It consists mainly of decomposition to different products and of the production of a "thermalized" Criegee biradical. The branching ratios of such relaxation processes change according to the functional groups present and to the size of the molecule. $\mathrm{OH}$ is only produced in one of these decompositions, namely the hydroperoxide channel (Niki et al., 1987). These thermalized biradicals in MCM are considered to react with $\mathrm{H}_{2} \mathrm{O}, \mathrm{CO}, \mathrm{NO}, \mathrm{NO}_{2}$ and $\mathrm{SO}_{2}$. For this, MIM2 follows the MCM protocol very closely. Since these relaxation reactions are very fast (higher than $1 \mathrm{~s}^{-1}$ ) compared to the typical integration time step of 3-D models ( $\approx 30 \mathrm{~min}$.), MIM2 assumes that all ozonolysis reactions directly yield the corresponding final products. The thermalized Criegee biradicals are assumed to react only with $\mathrm{H}_{2} \mathrm{O}$ since this is the predominant fate under tropospheric conditions (Jenkin et al., 1997).

\subsection{The $\mathrm{NO}_{3}$-pathway}

For the oxidation of isoprene by $\mathrm{NO}_{3}$ MIM2 follows MCM closely until LISOPACNO3 and NC4CHO are formed. Only the reaction of the peroxy radical NISOPO2 (from
ISOP + NO3) with $\mathrm{NO}_{3}$ is neglected. It is worth noting that this radical was represented in MIM by the lumped species ISON (see Sect. 3.6.1), being treated as a long-lived species and not like an $\mathrm{RO}_{2}$. Finally, the peroxy radicals from this pathway are treated similarly to the ones from the $\mathrm{OH}-$ pathway.

\subsection{Unsaturated $\mathrm{C}_{5}-\mathrm{C}_{4}$-products}

The treatment of hydroperoxides, diols and alkyl nitrates was discussed above in Sect. 2.4. Except for two species being lumped (LISOPACOOH and LISOPACNO3), their chemistry strictly follows MCM. Here we discuss the treatment of two other important $\mathrm{C}_{4}-\mathrm{C}_{5}$ groups.

\subsubsection{Aldehydes}

With respect to MACR (methacrolein) and its products like PAN, MIM2 follows MCM closely. The fate of the $\mathrm{C}_{5}-\delta$ hydroxy-carbonyls (LHC4ACCHO) is considered to be the average of the equally weighted reactions for $\mathrm{HC} 4 \mathrm{ACHO}$ and $\mathrm{HC} 4 \mathrm{CCHO}$ (MCM species). The OH-pathway for $\mathrm{NC} 4 \mathrm{CHO}$ produces the lumped species LNISO3, consisting of equal parts of $\mathrm{NC} 4 \mathrm{CO} 3$ (carboxylic $\mathrm{RO}_{2}$ ) and $\mathrm{C} 510 \mathrm{O} 2$ (alkyl $\mathrm{RO}_{2}$ ). The subsequent reactions result from averaging both reactivities and product yields. 
- MCM low-NOX

MIM IOW-NOX

MIMVK IOW-NOX

- MIM2 IOW-NOX

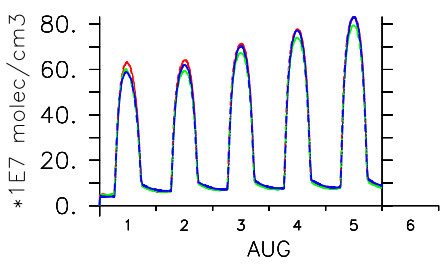

$\mathrm{HO} 2$
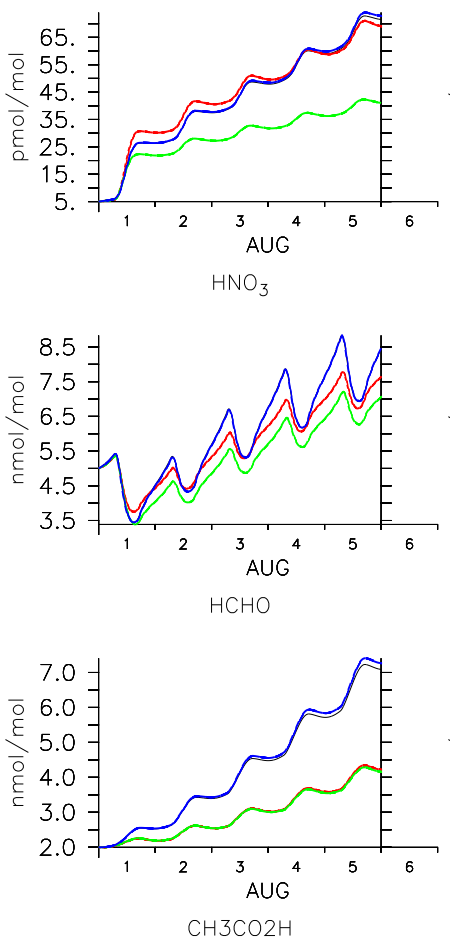
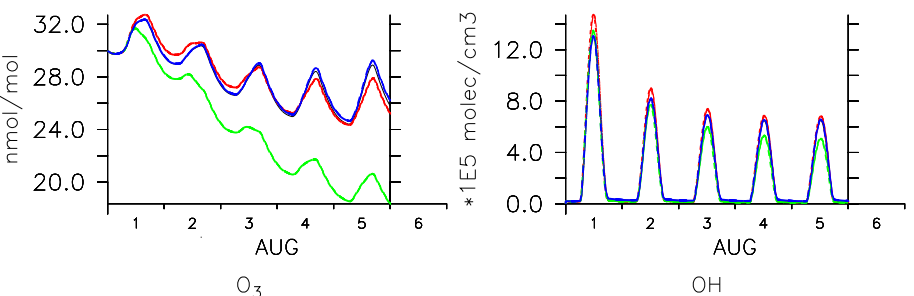

$\mathrm{OH}$

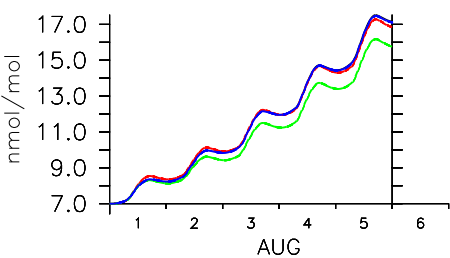

$\mathrm{H}_{2} \mathrm{O}_{2}$
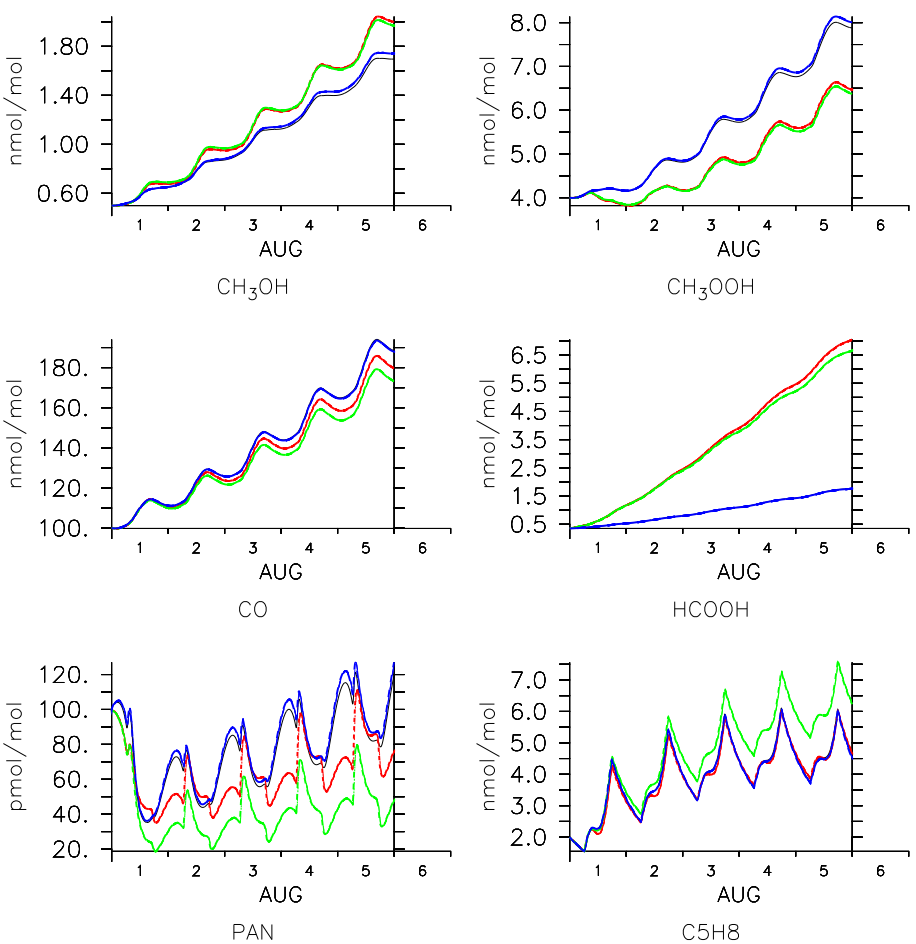

Fig. 2. Low- $\mathrm{NO}_{\mathrm{x}}$ scenario: comparison of MCM, MIM, MIMvK and MIM2.

\subsubsection{Ketones}

For the chemistry of MVK (methyl vinyl ketone) MIM2 does not neglect any products. The $\mathrm{OH}$-addition to it results in the production of a lumped species, LHMVKABO2, having the composition 0.3 HMVKAO2 + 0.7 HMVKBO2 (MCM species). A similar treatment is followed for $\mathrm{MVKOH}$, and almost all the corresponding products are taken into account. However, a product of MVKOH photolysis, ALLYLOH (2propen-1-ol), is neglected. The only $\mathrm{C}_{5}$-ketone, $\mathrm{HCOC} 5$, is treated like in MCM.

\section{$2.8 \mathrm{C}_{3}-\mathrm{C}_{2}$-products}

The chemistry of $\mathrm{C}_{3}-\mathrm{C}_{2}$ products in MIM2 is explicit and close to MCM. Species like methylglyoxal and hydroxyacetone are not lumped together with other species as was the case in MIM. New species like propene, nitrooxy acetone, glycoladehyde, and glyoxal are present. In the case of propene the minor products of $\mathrm{OH}$ - and $\mathrm{NO}_{3}$-addition, namely IPROPOLO2 and PRONO3AO2, are neglected since they behave similarly to the more abundant products. The peroxy acyl nitrate GLYPAN from glyoxal is neglected because it is found to be below $30 \mathrm{pmol} / \mathrm{mol}$ under all $\mathrm{NO}_{\mathrm{x}}$ conditions studied. 
MCM IOW - NOX

MIM low-NOX

MIMvK IOw-NOX

. . MIM2 low-NOX
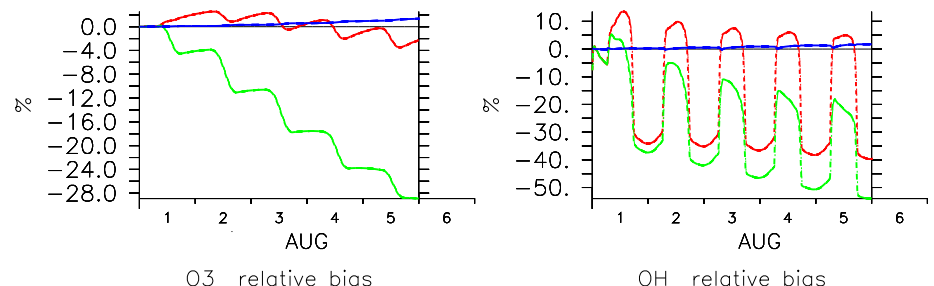

$\mathrm{OH}$ relative bias
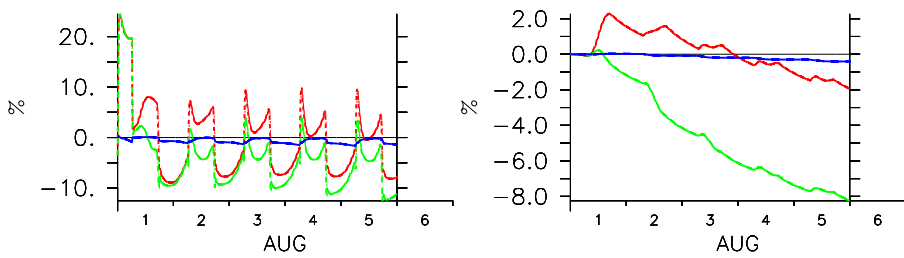

$\mathrm{H} 2 \mathrm{O} 2$ relative bias

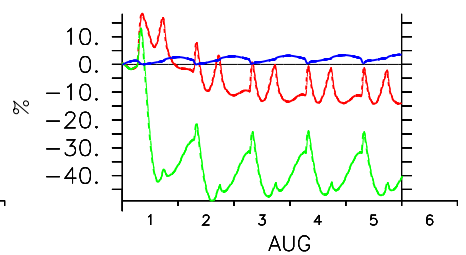

$\mathrm{HO} 2$ relative bias

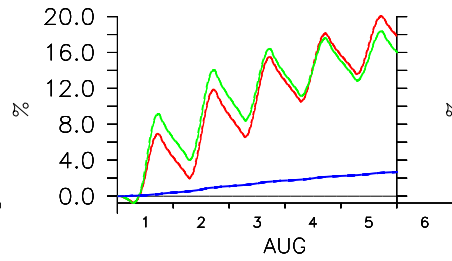

NOx bias

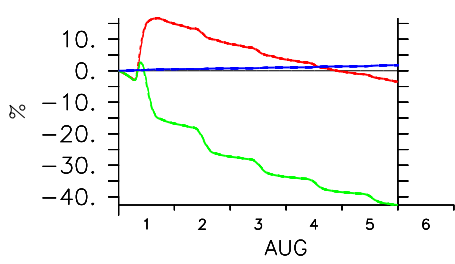

HNO3 relative bias

$\mathrm{CH} 30 \mathrm{H}$ relative bias

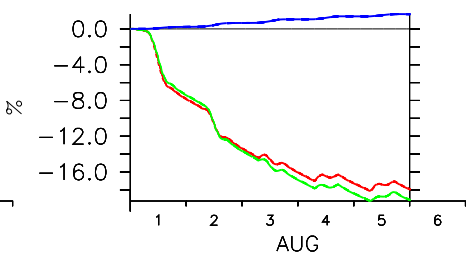

$\mathrm{CH} 300 \mathrm{H}$ relative bias
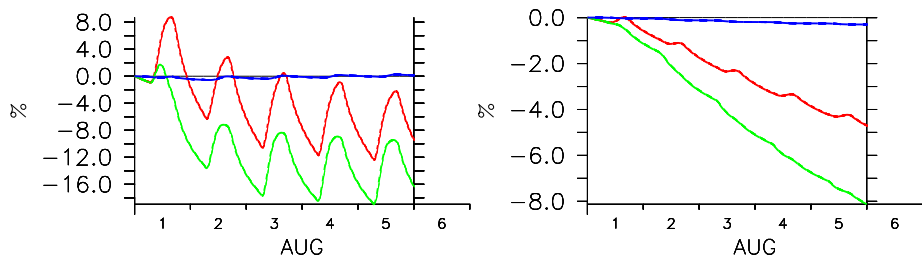

CO relative bias

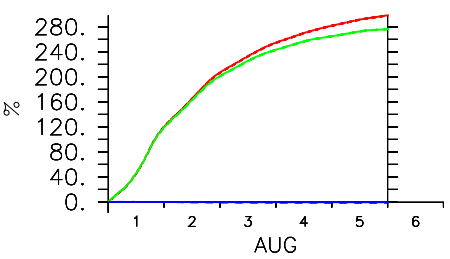

$\mathrm{HCHO}$ relative bias

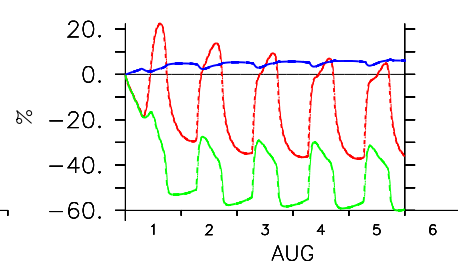

$\mathrm{HCOOH}$ relative bias

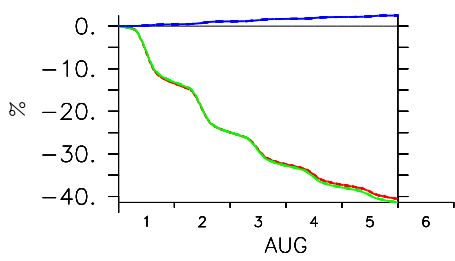

$\mathrm{CH} 3 \mathrm{CO} 2 \mathrm{H}$ relative bias

PAN relative bias

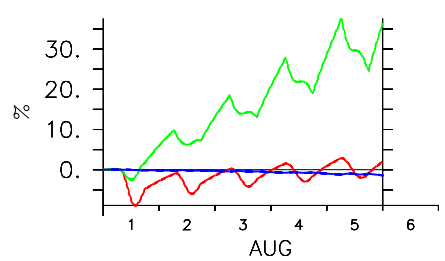

$\mathrm{C} 5 \mathrm{H} 8$ relative bias

Fig. 3. Low- $\mathrm{NO}_{\mathrm{x}}$ scenario: relative biases, $100 *($ mechanism-MCM)/MCM, of MIM, MIMvK and MIM2.

\section{MIM2 evaluation}

\subsection{Box model setup}

The box model MECCA (Sander et al., 2005) was used for this study. The model includes a kinetic preprocessor which automatically generates optimized Fortran90 code for the specific set of reactions. KPP-2.1 (Sandu and Sander, 2006), and the Rosenbrock 3rd order solver was used (Sandu et al., 1997). From the comprehensive set of reactions, a subset of tropospheric gas-phase reactions was selected. Reactions of sulfur and halogen species were switched off in the model simulations. The box is considered to be $1 \mathrm{~km}$ long on each side and to be representative of the boundary layer. All the simulations start on 1st August 2000, at midnight and the latitude is set to $10^{\circ} \mathrm{S}$, corresponding roughly to the Amazon forest. The relative humidity and the pressure are set to be $70 \%$ and $101325 \mathrm{~Pa}$, respectively. A diurnal cycle for light and temperature was applied. The function used for the temperature cycle is a sinusoidal (Heard et al., 1998) with values varying between 294 and $308 \mathrm{~K}$ and an average of $301 \mathrm{~K}$ :

$T=301+7 \times \sin \left(\frac{2 \pi}{86400} \times t-1.9635\right)$ 

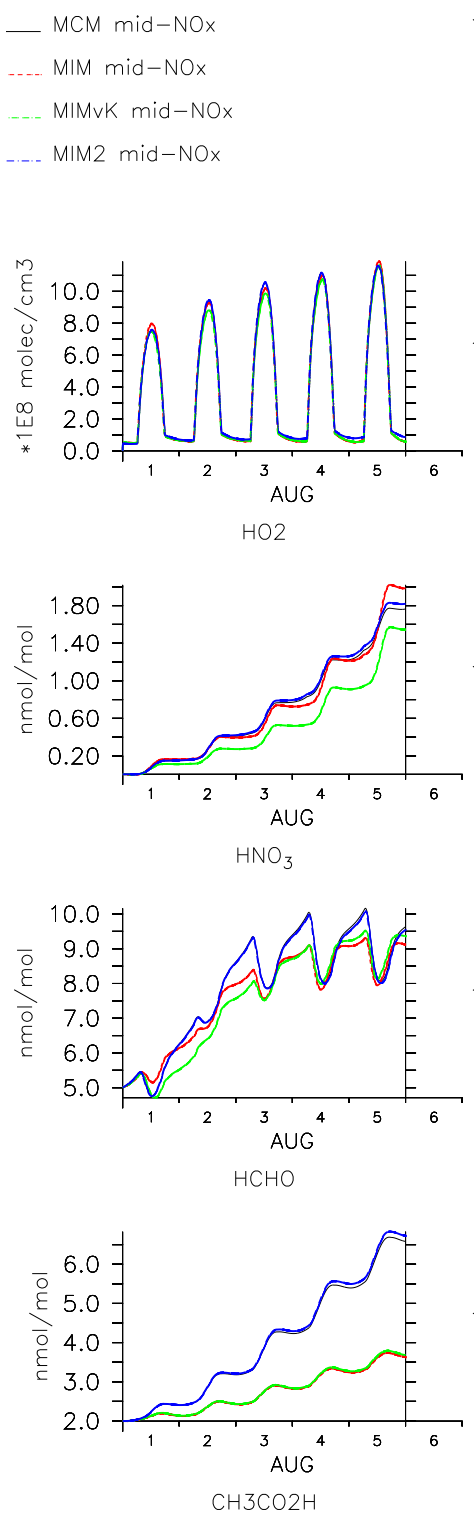
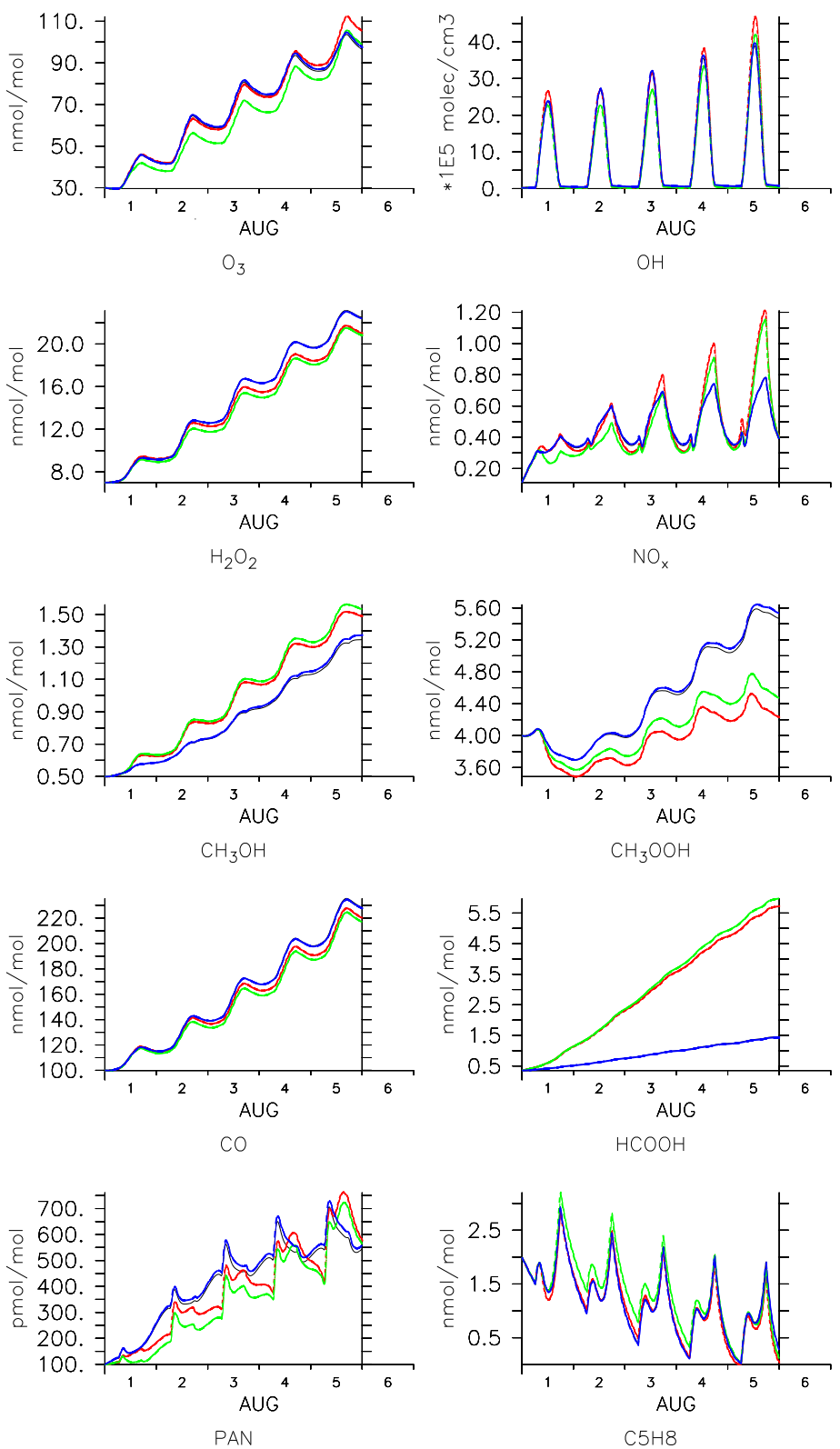

Fig. 4. Mid-NO $\mathrm{NO}_{\mathrm{x}}$ scenario: comparison of MCM, MIM, MIMvK and MIM2.

where $t$ is the time in seconds. The photolysis rates from MCM v3.1 are used (Saunders et al., 2003) for MCM, MIM and MIM2, while the solar zenith angle dependency used was the one included in MECCA. Only species that are not lumped in any of the mechanisms studied here were initialized with non-zero mixing ratios (see Table 2). For simplicity the initialization does not change in any of the $\mathrm{NO}_{\mathrm{x}}$ scenarios presented here. The isoprene flux was calculated using the equations given in Guenther et al. (1995) and assuming an average photosynthetically active radiation (PAR) flux of $1000 \mu \mathrm{mol} \mathrm{m}^{-2} \mathrm{~s}^{-1}$. The maximum isoprene flux reached at noon was $7.887 \times 10^{11}$ molecule $\mathrm{cm}^{-2} \mathrm{~s}^{-1}$. Guenther et al. (2006) present a more sophisticated calculation of the isoprene emission depending on many more parameters compared to the one presented in Guenther et al. (1995). However, the differences in global estimates are $67 \mathrm{Tg} / \mathrm{yr}$, well below the uncertainty range of the estimates themselves. Moreover, for a box model evaluation of mechanisms for isoprene oxidation any emission function can be used. The use of such a function serves the purpose of having a diurnal cycle for the isoprene emission that is not far off from reality. The base NO flux was constant and equal 


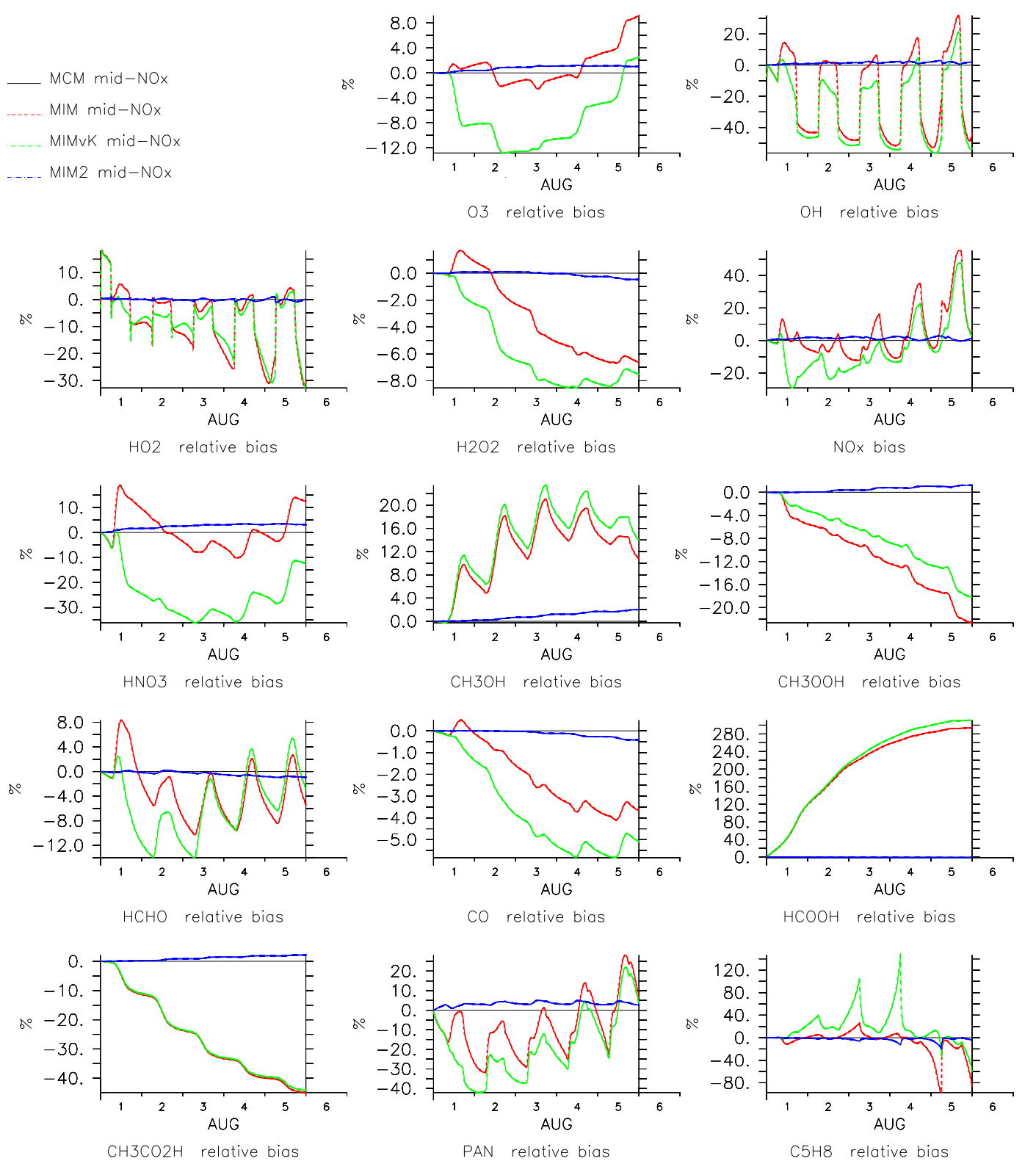

Fig. 5. Mid-NO $\mathrm{NO}_{\mathrm{x}}$ scenario: relative biases, $100 *($ mechanism-MCM)/MCM, of MIM, MIMvK and MIM2.

to $3.33 \times 10^{9}$ molecule $\mathrm{cm}^{-2} \mathrm{~s}^{-1}$. Three main $\mathrm{NO}_{\mathrm{x}}$ scenarios were examined. One is the base emission scenario noted above and the other two are 10 and 100 times higher than the base emission rate, respectively. They will be referred to as, the low-, mid- and high- $\mathrm{NO}_{\mathrm{x}}$ scenarios, respectively. Besides the isoprene and the $\mathrm{NO}_{\mathrm{x}}$ emissions, no further emission or deposition of species was included in the simulations. As can be seen in Figs. 2 and 4, a comparison of three reduced mechanisms versus MCM is performed. These mechanisms are:
- MIM2 (this study)

- MIM (Pöschl et al., 2000).

- MIMvK, which is MIM as implemented in Sander et al. (2005) and Jöckel et al. (2006). This version differs from the original one with the alkyl nitrate yield being increased from $4.4 \%$ to $12 \%$ as assumed by (von Kuhlmann et al., 2004) based on (Sprengnether et al., 2002) and with a few updates of the rate constants. 


\subsection{Oxidation pathways of isoprene and $\mathrm{RO}_{2}$}

The destruction of isoprene and all its peroxy radicals has been budgeted and the corresponding cumulative losses are shown in Table 3 . The most important oxidation pathway for isoprene is reaction with $\mathrm{OH}$, ranging between $\approx 68$ and $80 \%$ of the total loss depending on the $\mathrm{NO}_{\mathrm{x}}$ mixing ratios. Reaction with $\mathrm{O}_{3}$ is relatively more important in low- $\mathrm{NO}_{\mathrm{x}}$ conditions $(\approx 31 \%)$. Finally, the reaction with $\mathrm{NO}_{3}$ turns out to account for less than $1 \%$ of the total isoprene loss in unpolluted environments but it can exceed $10 \%$ in high- $\mathrm{NO}_{\mathrm{x}}$ regimes.

The largest loss for the peroxy radicals in low- $\mathrm{NO}_{\mathrm{x}}$ conditions is the reaction with $\mathrm{HO}_{2}(\approx 51 \%)$, while under high$\mathrm{NO}_{\mathrm{x}}$ conditions the reaction with $\mathrm{NO}$ predominates $(\approx 75 \%)$. Reactions with $\mathrm{NO}_{3}$ are not very important under any of the conditions studied, though they can account for about $4 \%$ of the total loss under high- $\mathrm{NO}_{\mathrm{x}}$ conditions. It is worth noting that the self- and cross-reactions $\left(\mathrm{RO}_{2}+\mathrm{R}^{\prime} \mathrm{O}_{2}\right)$ account for about $25 \%$ of the total loss in low- $\mathrm{NO}_{\mathrm{x}}$. This confirms the importance of such reactions in the oxidation of organics in the gas-phase as indicated previously by Madronich and Calvert (1990).

\subsection{Low-NO $\mathrm{N}_{\mathrm{x}}$ regimes}

\subsubsection{MCM behaviour}

In this scenario the NO emission rate was set to be $3.33 \times 10^{9}$ molecule $\mathrm{cm}^{-2} \mathrm{~s}^{-1}$. In Fig. 2 the mixing ratios of the most important tracers are shown. The ozone mixing ratio shows that the chemical system is close to the turning point between the $\mathrm{O}_{3}$-producing (mid- $\mathrm{NO}_{\mathrm{x}}$ ) and $\mathrm{O}_{3}$-depleting (low- $\mathrm{NO}_{\mathrm{x}}$ ) regimes. $\mathrm{OH}$ and isoprene have reached an approximate photostationary state after 5 days, with maximum values of about $6.5 \cdot 10^{5}$ molecule $\mathrm{cm}^{-3}$ and $6 \mathrm{nmol} \mathrm{mol}{ }^{-1}$, respectively.

\subsubsection{MIM2 and MIM behaviour and biases}

In Fig. 3 the biases relative to MCM for the species presented in Fig. 2 are shown. MIM2, unlike MIM, is massconserving with respect to carbon, as can be seen from the $\mathrm{CO}$ and $\mathrm{HCHO}$ mixing ratios. For instance, in MIM there is the following non-mass conserving reaction,

$\mathrm{ISO}_{2} \mathrm{H}+\mathrm{OH} \rightarrow \mathrm{MACR}+\mathrm{OH}$

with a rate constant $k=10^{-10} \mathrm{~cm}^{3}$ molecule ${ }^{-1} \mathrm{~s}^{-1}$. In this reaction $\mathrm{ISO}_{2} \mathrm{H}$ is a $\mathrm{C}_{5}$-hydroperoxide and MACR reacts as a lumped $\mathrm{C}_{4}$-carbonyl within the mechanism. Moreover, the ozonolysis of isoprene and MACR is not mass-conserving in MIM either. In these two reactions, product yields account for only $4.28 \mathrm{C}$ atoms instead of 5, and 3.57 instead of 4 , respectively. These are not the only reactions in MIM where carbon mass disappears. The contribution of isoprene oxidation to $\mathrm{CO}$ production in the atmosphere has been estimated by Kanakidou and Crutzen (1999) to be $330 \mathrm{Tg} / \mathrm{yr}$, about $13.5 \%$ of the total estimated source. The MIM bias for $\mathrm{CO}$ grows steadily in absolute terms and reaches about $-5 \%$ after a 5 day simulation while the MIM2 bias reaches only $\approx-0.02 \%$. The CO-yield is thus higher in MIM2 compared to MIM. This might not hold in 3-D atmospheric model simulations because of dry deposition and scavenging. In fact, MIM2 differs remarkably from MIM with respect to the total alkyl nitrates and the hydroxy-peroxides from $\mathrm{C}_{2}$ to $\mathrm{C}_{5}$ (see Sect. 3.6). Such species are believed to be very soluble and reactive and can deposit efficiently with Henry's law coefficients in the range of $0.1-5 \cdot 10^{5} \mathrm{M} \mathrm{atm}^{-1}$ (Treves et al., 2000; Shepson et al., 1996; Sander, 1999, and references therein).

MIM neglects the formation of a few important species from isoprene oxidation: acetaldehyde $\left(\mathrm{CH}_{3} \mathrm{CHO}\right)$, glycolaldehyde $\left(\mathrm{HOCH}_{2} \mathrm{CHO}\right)$, glyoxal ( $\left.\mathrm{CHOCHO}\right)$, propene $\left(\mathrm{CH}_{3} \mathrm{CH}=\mathrm{CH}_{2}\right)$ and $\alpha$-nitrooxy acetone $\left(\mathrm{CH}_{3} \mathrm{C}(\mathrm{O}) \mathrm{CH}_{2} \mathrm{OONO}_{2}\right.$ ) (see Table 3 and Supplementary Information for MIM2 comparisons with MCM results). They are not considered, neither as single species, nor as part of lumped species. MIM2 drastically reduces the bias for species like formaldehyde $(\mathrm{HCHO})$, peroxy acetyl nitrate (PAN), carbon monoxide $(\mathrm{CO})$, acetic acid $\left(\mathrm{CH}_{3} \mathrm{C}(\mathrm{O}) \mathrm{OH}\right)$, formic acid $(\mathrm{HCOOH})$ and methanol $\left(\mathrm{CH}_{3} \mathrm{OH}\right)$ by the improved treatment of ozonolysis reactions, in particular the reaction ISOP $+\mathrm{O}_{3}$ (see Sect. 2.5). From a simple budgeting (see Table 3), this latter reaction turns out to account for about $31 \%$ of the total destruction of isoprene in the low- $\mathrm{NO}_{\mathrm{x}}$ scenario. It can be seen from Fig. 3 how these MIM biases for the above mentioned species increase over night. In particular, the large MIM bias for PAN (up to nearly $-40 \%$ ) is due to a much lower yield of $\mathrm{CH}_{3} \mathrm{CO}_{3}$ from the ozonolysis reactions. This yield from the isoprene ozonolysis is equal to 0.1 in MIM, versus 0.1575 in MIM2. These biases for MIM are all negative except for $\mathrm{HCOOH}$ and $\mathrm{CH}_{3} \mathrm{OH}$. The production of methyl peroxy radical $\left(\mathrm{CH}_{3} \mathrm{O}_{2}\right)$ within MIM2 is essential to adequately reproduce the mixing ratios of methanol $\left(\mathrm{CH}_{3} \mathrm{OH}\right)$ and methyl hydroperoxide $\mathrm{CH}_{3} \mathrm{OOH}$. The atmospheric production of $\mathrm{CH}_{3} \mathrm{OH}$ through the permutation reactions of $\mathrm{CH}_{3} \mathrm{O}_{2}$ was estimated recently to be about $38 \mathrm{Tg} / \mathrm{yr}$ (Jacob et al., 2005; Millet et al., 2008). This amounts to nearly $16 \%$ of the total estimated global source, and MIM2 reduces the uncertainties in this term. The overestimation of $\mathrm{CH}_{3} \mathrm{OH}$ in MIM is due to a too high $\mathrm{CH}_{3} \mathrm{O}_{2}$ yield from the ozonolysis reactions. On the other hand the $\mathrm{CH}_{3} \mathrm{OOH}$ underestimation is due to the complete absence of $\mathrm{CH}_{3} \mathrm{O}_{2}$ production from the reactions of the $\mathrm{C}_{5}$-peroxy radicals and peroxides. These two reactions turn out to be important for $\mathrm{CH}_{3} \mathrm{OOH}$ production because they take place mostly during daytime when the $\mathrm{HO}_{2}$ concentration peaks. The production of $\mathrm{CH}_{3} \mathrm{O}_{2}$ in MCM takes place in the decomposition channel of the tertiary alkoxy radical ISOPBO that yields hydroxy-methyl vinyl ketone, MVKOH. 

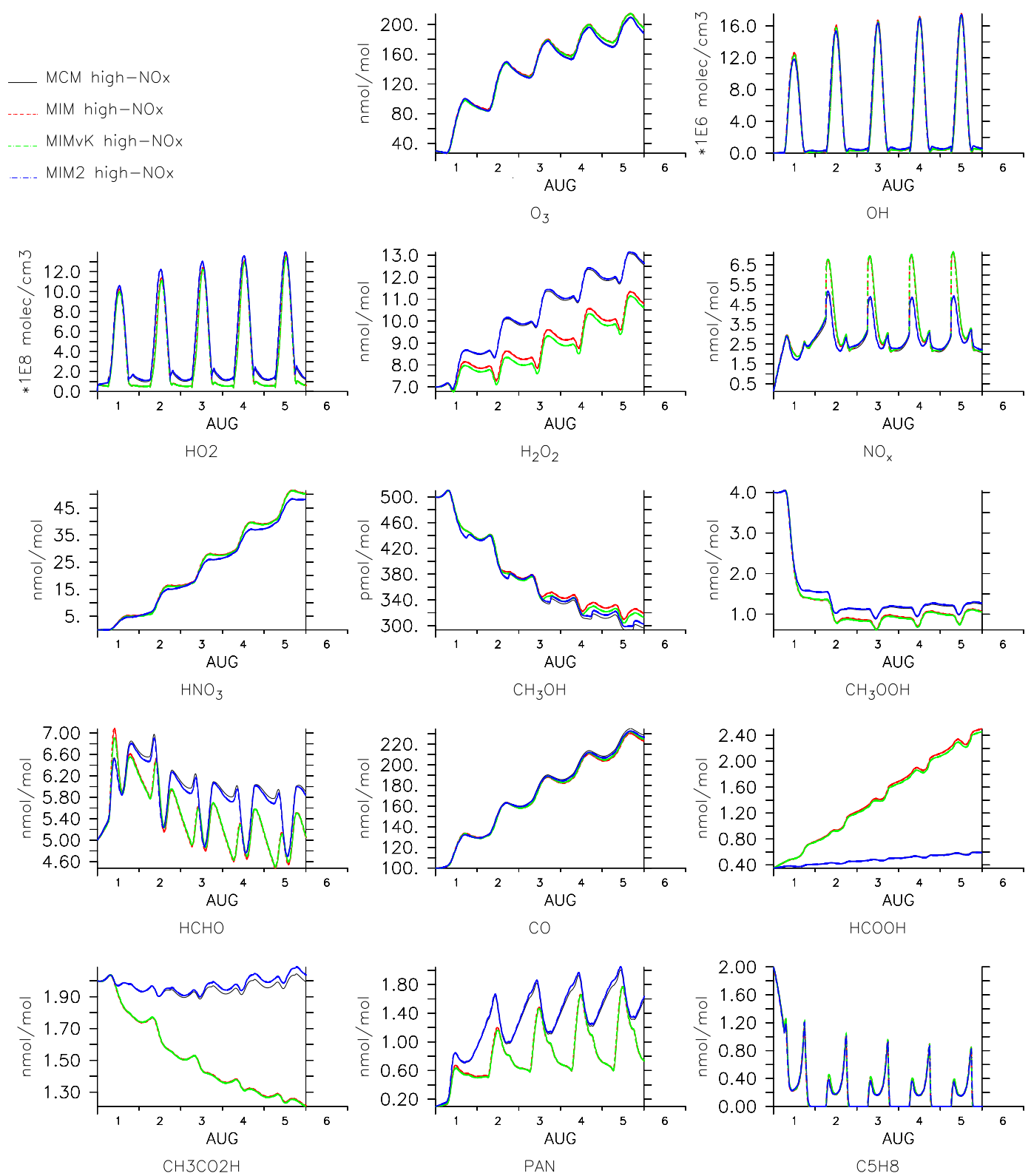

Fig. 6. High- $\mathrm{NO}_{\mathrm{x}}$ scenario: comparison of MCM, MIM, MIMvK and MIM2.

Unlike MIM, the MIM2 biases for the species in Fig. 3 are always lower than $6 \%$. They often have constant sign and grow slowly. Overall the mechanism referred to as MIMvK performs very poorly in computing $\mathrm{O}_{3}$ and isoprene under these conditions. This is due to the representation of the alkyl nitrates (see Sect. 3.6.1). The amount of $\mathrm{NO}_{\mathrm{x}}$ that is sequestered by the alkyl nitrates is too high, so that $\mathrm{OH}$ and $\mathrm{O}_{3}$ are reduced substantially. Such differences between MIMvK and MIM are not seen when the NO emissions are increased by a factor of 10 , as discussed in the next section.

\subsection{Mid-NO $\mathrm{X}_{\mathrm{x}}$ regimes}

\subsubsection{MCM behaviour}

In this scenario the NO emission rate was set to be $3.33 \times 10^{10}$ molecule $\mathrm{cm}^{-2} \mathrm{~s}^{-1}$. In Fig. 4 the mixing ratios of the most important tracers are shown. The ozone and $\mathrm{NO}_{\mathrm{x}}$ mixing ratios clearly show that the system is in the $\mathrm{O}_{3^{-}}-$ producing regime. The $\mathrm{OH}$ concentration keeps increasing and reaches values of about one order of magnitude higher than seen in the low- $\mathrm{NO}_{\mathrm{x}}$ scenario (cf. Fig. 2). After 5 days, it peaks at about $4 \cdot 10^{6}$ molecule $\mathrm{cm}^{-3}$. None of the species, ex- 


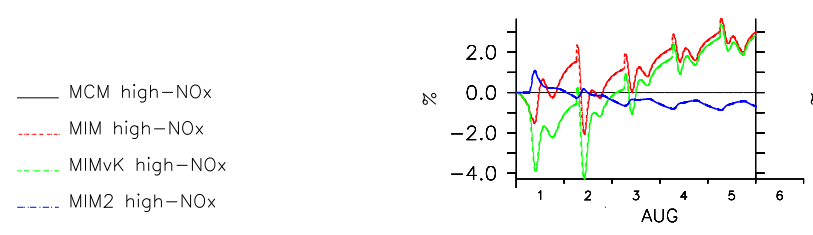

03 relative bias

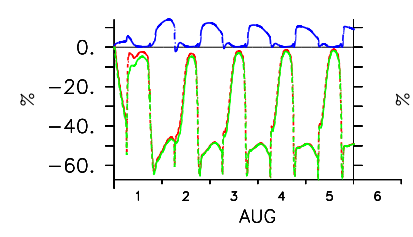

HO2 relative bias

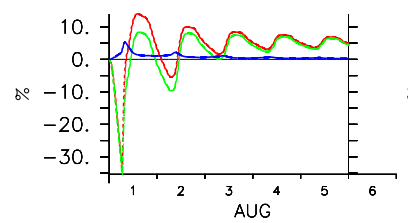

HNO3 relative bias

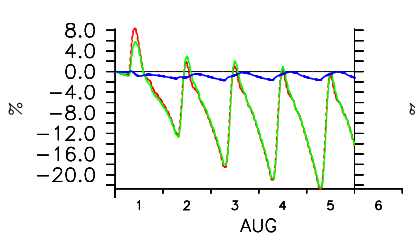

$\mathrm{HCHO}$ relative bias

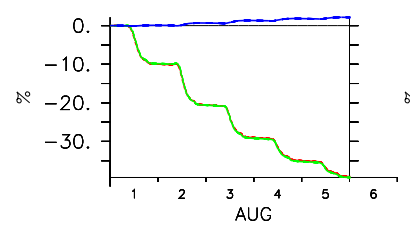

$\mathrm{CH} 3 \mathrm{CO} 2 \mathrm{H}$ relative bias

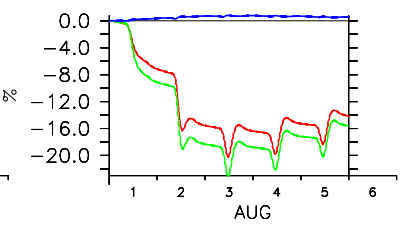

$\mathrm{H} 2 \mathrm{O} 2$ relative bias

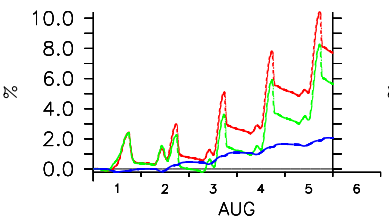

$\mathrm{CH} 3 \mathrm{OH}$ relative bias

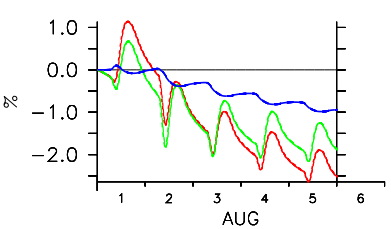

CO relative bias

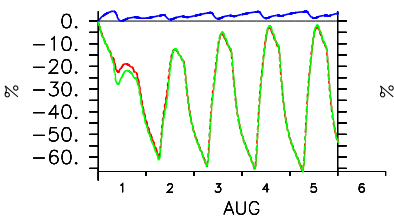

PAN relative bias

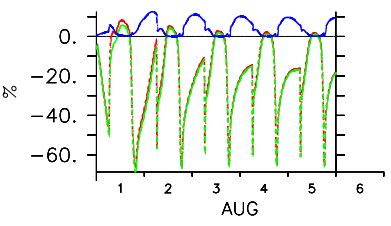

$\mathrm{OH}$ relative bias

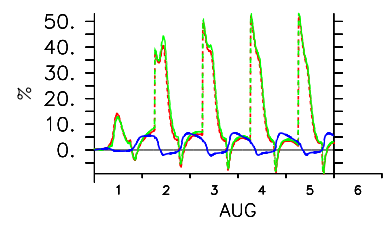

NOx bias

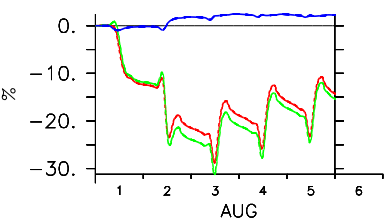

$\mathrm{CH} 300 \mathrm{H}$ relative bias

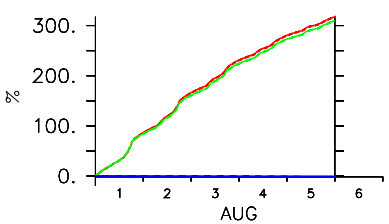

$\mathrm{HCOOH}$ relative bias

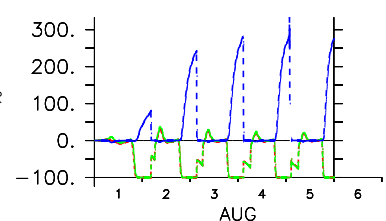

$\mathrm{C} 5 \mathrm{H} 8$ relative bias

Fig. 7. High- $\mathrm{NO}_{\mathrm{x}}$ scenario: relative biases, $100 *($ mechanism-MCM)/MCM, of MIM, MIMvK and MIM2.

$$
\begin{aligned}
& \text { _ MIM2 low-NOx } \\
& \text { _... MIM2 mid-NOx } \\
& \text {... MIM2 high-NOX }
\end{aligned}
$$

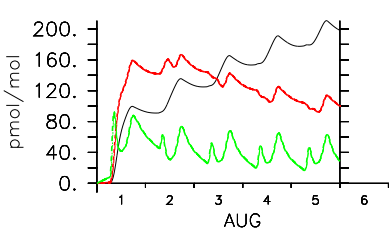

C5-nitrates from $\mathrm{RO} 2+\mathrm{NO}$

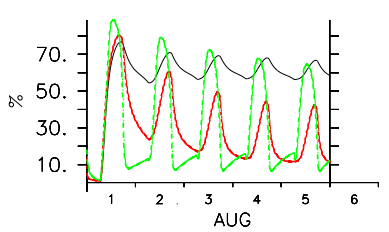

C5-nitrates from $\mathrm{RO} 2+\mathrm{NO}$

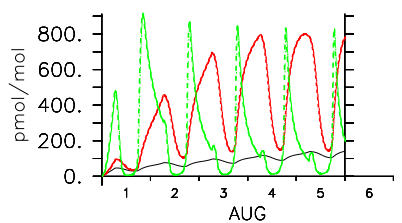

C5-nitrates from ISOP + NO3

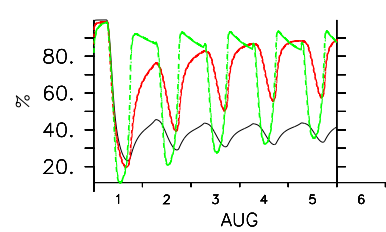

C5-nitrates from ISOP + NO3

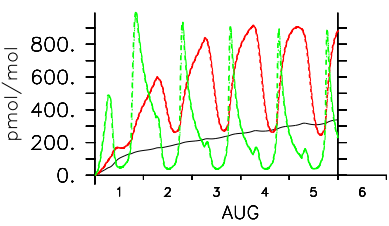

Total C5-nitrates

Fig. 8. Alkyl nitrates in MIM2 under different $\mathrm{NO}_{\mathrm{x}}$-regimes 

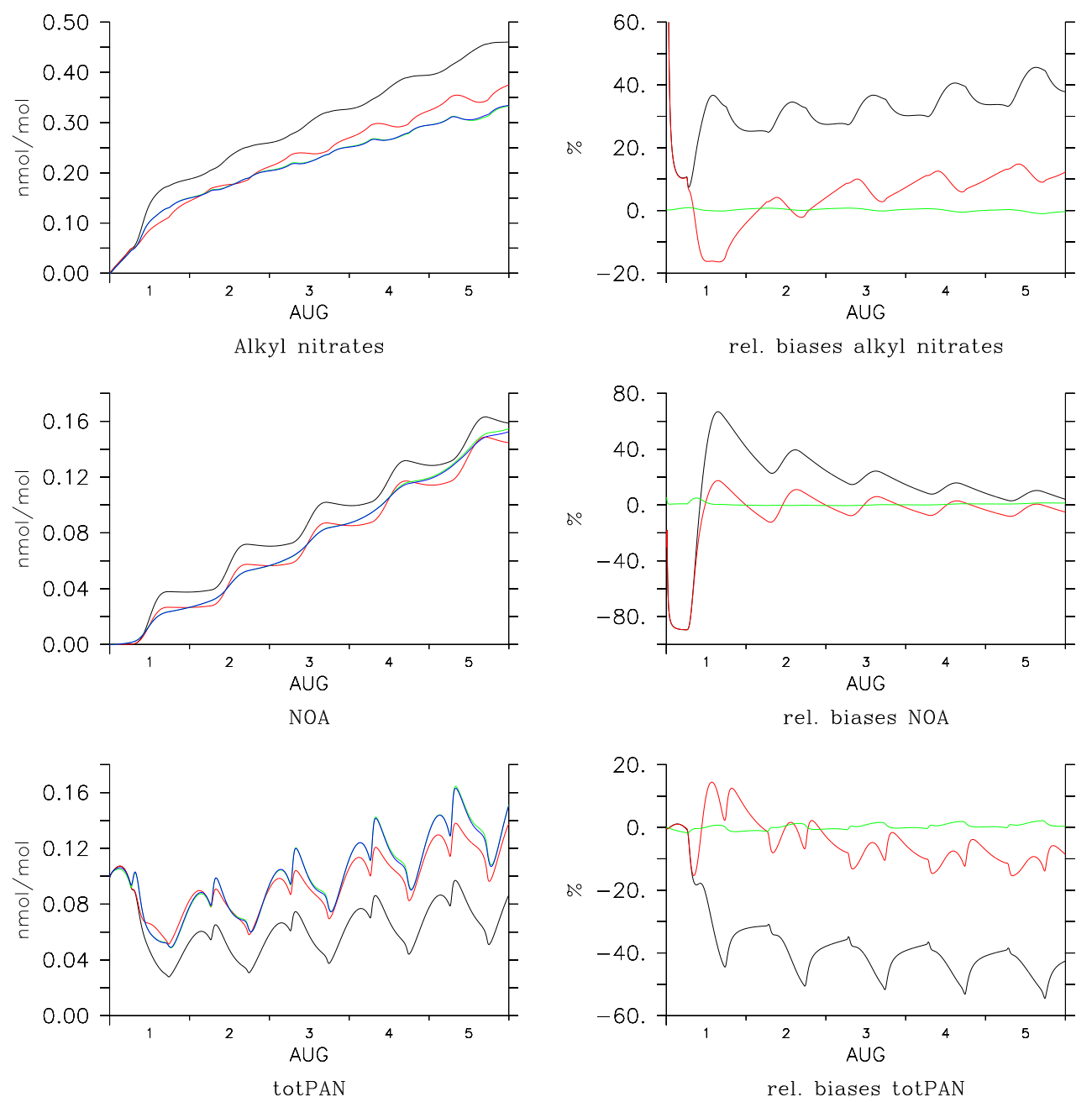

Fig. 9. Nitrogen reservoirs in low- $\mathrm{NO}_{\mathrm{x}}$ scenario. In all the plots the actual mixing ratios of each species are presented with MIMvK (black line), original MIM (red line), MIM2 (green line) and MCM (blue line). The alkyl nitrates shown here are the sum of all alkyl nitrates except NOA (shown separately).

cept isoprene and $\mathrm{HCHO}$, reach photostationary state. Compared to the low- $\mathrm{NO}_{\mathrm{x}}$ scenario, both $\mathrm{NO}_{\mathrm{x}}$ and PAN have a different diurnal cycle. Their mixing ratios do not have a secondary maximum shortly after midnight and continue to peak in the late afternoon and in the morning, respectively.

\subsubsection{MIM2 and MIM behaviour and biases}

Between the fourth and the fifth day of simulation time isoprene in MCM is depleted to nearly zero (see Fig. 4). Small differences in absolute terms between the different mechanisms are expected to result in quite large relative biases. For instance, when MCM computes isoprene concentrations very close to zero (during nighttime), both MIM and MIM2 give the largest relative biases with respect to isoprene itself (see Fig. 5). There is no clear tendency for the MIM2 average relative biases for all species to be better or worse for this sce- nario compared to the low- $\mathrm{NO}_{\mathrm{x}}$ scenario (cf. Figs. 3 and 5). Even though the sign changes for some, they remain whithin the 5\% range (see Table 3). The other two reduced mechanisms, MIM and MIMvK, show many biases similar to the biases in the low- $\mathrm{NO}_{\mathrm{x}}$ scenario. What is striking, however, are the large biases with respect to $\mathrm{OH}, \mathrm{NO}_{\mathrm{x}}$ and PAN. The explanation lies in the differences regarding the organic nitrogen reservoirs in such mechanisms (see Sect. 3.6). The MIM bias for $\mathrm{OH}$ reaches $+30 \%$ during daytime while for $\mathrm{NO}_{\mathrm{x}}$ it reaches more than $+50 \%$. It is worth noting that in contrast to the low- $\mathrm{NO}_{\mathrm{x}}$ scenario, the MIM relative bias for $\mathrm{H}_{2} \mathrm{O}_{2}$ starts to be substantial, reaching $\approx-7 \%$. The $\mathrm{H}_{2} \mathrm{O}_{2}-$ yield from ozonolysis of isoprene is $11 \%$ in MIM2 and 9\% in MIM. Moreover, the ozonolysis of $\mathrm{C}_{5}$ - and $\mathrm{C}_{4}$-carbonyls in MIM does not produce $\mathrm{H}_{2} \mathrm{O}_{2}$. 

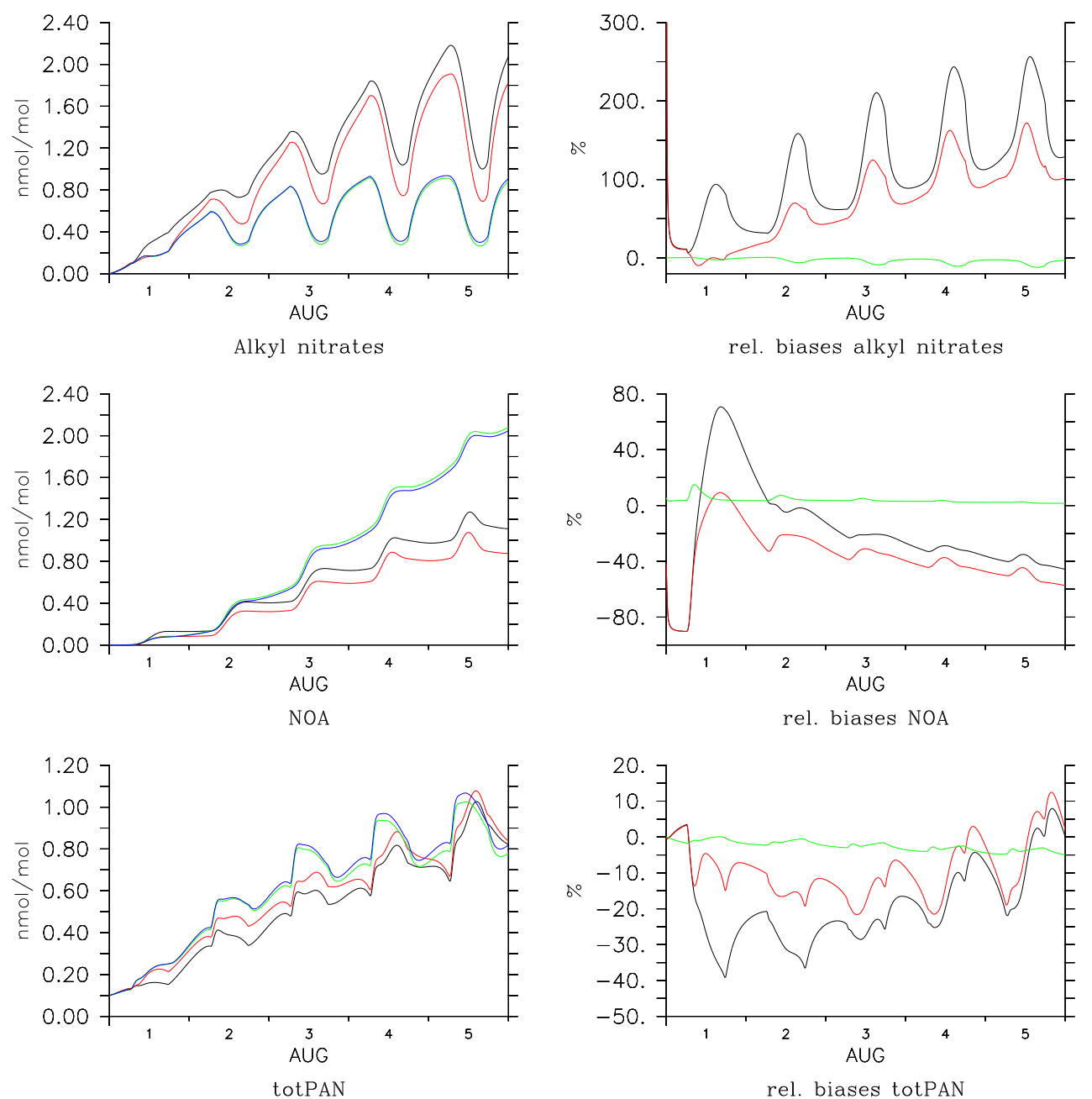

Fig. 10. Nitrogen reservoirs in mid- $\mathrm{NO}_{\mathrm{x}}$ scenario. In all the plots the actual mixing ratios of each species are presented with MIMvK (black line), original MIM (red line), MIM2 (green line) and MCM (blue line). The alkyl nitrates shown here are the sum of all alkyl nitrates except NOA (shown separately).

\subsection{High- $\mathrm{NO}_{\mathrm{x}}$ regimes}

\subsubsection{MCM behaviour}

In this scenario the $\mathrm{NO}$ emission rate was set to $3.33 \times 10^{11}$ molecule $\mathrm{cm}^{-2} \mathrm{~s}^{-1}$. In Fig. 6 the mixing ratios of the most important tracers are shown. $\mathrm{O}_{3}$ is produced very efficiently, reaching $200 \mathrm{nmol} \mathrm{mol}^{-1}$, and $\mathrm{OH}$ peaks with concentrations always higher than $1 \cdot 10^{7}$ molecule $\mathrm{cm}^{-3}$. PAN reaches values of $1.5 \mathrm{nmol} \mathrm{mol}^{-1}$ and $\mathrm{HCHO}$ reaches photostationary state after 3 days simulation time. $\mathrm{NO}_{\mathrm{x}}$ peaks in the morning at values around $5 \mathrm{nmol} \mathrm{mol}^{-1}$ and a large part of the total nitrogen is stored as $\mathrm{HNO}_{3}$, reaching a mixing ratio of more than $45 \mathrm{nmol} \mathrm{mol}^{-1}$ at the end of the simulation. $\mathrm{HCOOH}$ and $\mathrm{CH}_{3} \mathrm{C}(\mathrm{O}) \mathrm{OH}$ mixing ratios grow much less compared to the other $\mathrm{NO}_{\mathrm{x}}$ scenarios.

\subsubsection{MIM2 and MIM behaviour and biases}

Under the high- $\mathrm{NO}_{\mathrm{x}}$ regime both MIM and MIM2 show modest relative biases for $\mathrm{O}_{3}$ being always within $1 \%$ (see Fig. 7). As expected, MIM2 has a large average relative bias of $-62.4 \%$ for isoprene and $-150 \%$ for NO (see Table 3 ) that correspond, however, to small absolute biases when the mixing ratios are at night close to zero. Moreover, glyoxal shows a substantial average relative bias of about $11 \%$ mostly due to the lumping in the $\mathrm{NO}_{3}$-pathway (see Table 3 in the Supplementary Material http://www.atmos-chem-phys. net/9/2751/2009/acp-9-2751-2009-supplement.pdf). This bias grows significantly at night and becomes close to zero during the day (see Fig. 3 in the Supplementary Material http://www.atmos-chem-phys.net/9/2751/ 2009/acp-9-2751-2009-supplement.pdf). In fact, the species LNISO3 is a lumped species representing two different kinds 

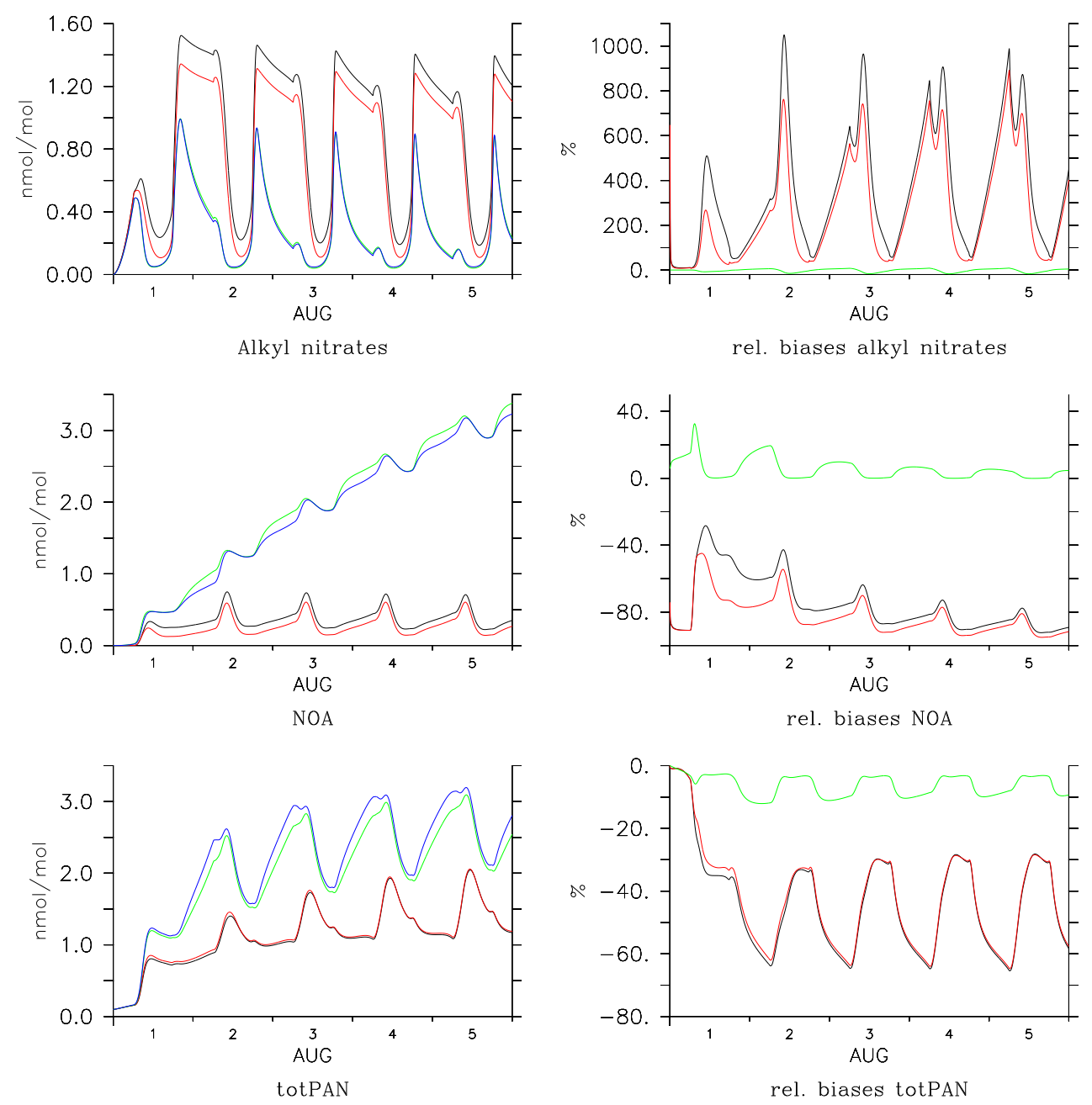

Fig. 11. Nitrogen reservoirs in high- $\mathrm{NO}_{\mathrm{x}}$ scenario. In all the plots the actual mixing ratios of each species are presented with MIMvK (black line), original MIM (red line), MIM2 (green line) and MCM (blue line). The alkyl nitrates shown here are the sum of all alkyl nitrates except NOA (shown separately).

of $\mathrm{RO}_{2}$, with one being alkyl and the other one acyl and having glyoxal and NOA as a reaction products, respectively. Besides isoprene, glyoxal and NO, there is no clear tendency for the MIM2 average relative biases for all other species to be better or worse for this scenario compared to the other $\mathrm{NO}_{\mathrm{x}}$ scenarios (cf. Figs. 3, 5 and 7). The MIM relative bias for $\mathrm{H}_{2} \mathrm{O}_{2}$ becomes rather large, reaching $\approx-20 \%$. Under such high- $\mathrm{NO}_{\mathrm{x}}$ regimes, isoprene ozonolysis contributes litthe to the production of $\mathrm{H}_{2} \mathrm{O}_{2}$ because it accounts for only $\approx 8 \%$ of the total isoprene destruction (see Table 3 ). The $\mathrm{OH}-$ and $\mathrm{NO}_{3}$-pathways now account for $\approx 92 \%$ of the isoprene destruction, while in the mid- $\mathrm{NO}_{\mathrm{x}}$ and low- $\mathrm{NO}_{\mathrm{x}}$ scenarios they account for $\approx 81$ and $69 \%$, respectively. The total yield of the $\mathrm{C}_{5}$-carbonyls in the high- $\mathrm{NO}_{\mathrm{x}}$ scenario is increased because they are not produced in the $\mathrm{O}_{3}$-pathway. The ozonolysis of such species in MIM does not produce any $\mathrm{H}_{2} \mathrm{O}_{2}$.

\subsection{Organic nitrogen and peroxides}

\subsubsection{Alkyl nitrates}

There are eight alkyl nitrates included and they can be subdivided in three groups (see Table 1 in the Supplementary Material http://www.atmos-chem-phys.net/9/2751/ 2009/acp-9-2751-2009-supplement.pdf). The first group includes three $\mathrm{C}_{5}$-alkyl nitrates produced by $\mathrm{RO}_{2}+\mathrm{NO}$ reactions in the OH-pathway. One has an internal double bond (LISOPACNO3) and two have an external double bond (ISOPBNO3 and ISOPDNO3). The second group includes three alkyl nitrates produced by the $\mathrm{NO}_{3}$-pathway with $\mathrm{NC} 4 \mathrm{CHO}$ and NISOPOOH having an internal double bond and LNISOOH with all carbon atoms being saturated. Finally, the third group includes two $\mathrm{C}_{3}$-alkyl nitrates. One is $\alpha$-nitrooxy acetone (NOA), which is produced 

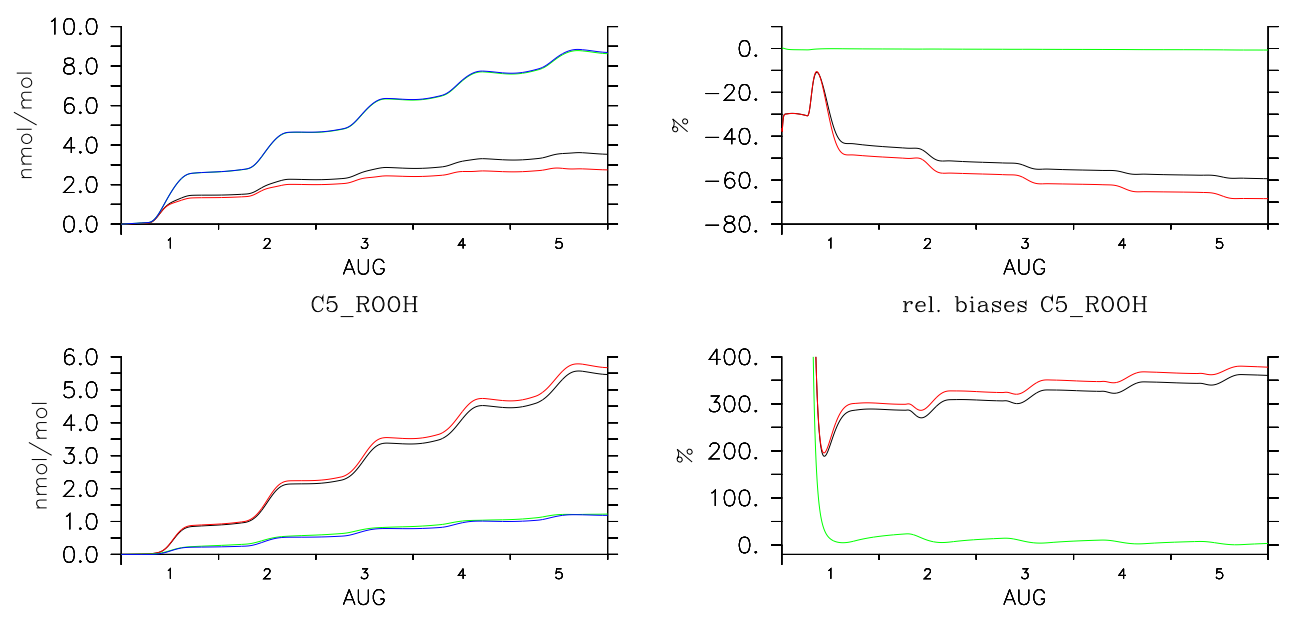

C4_ROOH
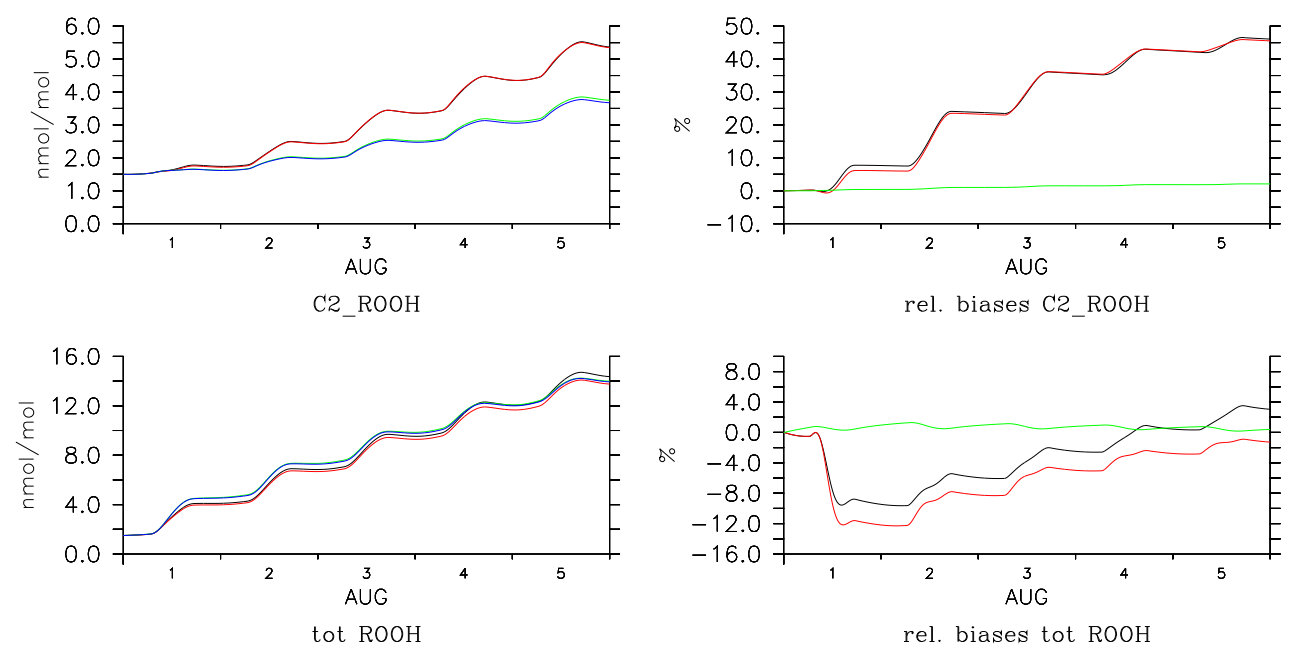

rel. biases tot $\mathrm{ROOH}$

Fig. 12. Organic peroxides other than $\mathrm{CH}_{3} \mathrm{OOH}$ for all four mechanisms in this study under low- $\mathrm{NO}_{\mathrm{x}}$ conditions. In all the plots the actual mixing ratios of each species are presented with MIMvK (black line), original MIM (red line), MIM2 (green line) and MCM (blue line). $\mathrm{C}_{3}$-peroxides are not shown because MIM and MIMvK do not have any.

during the oxidation of the above mentioned alkyl nitrates. The other one is PR2O2HNO3 (see Table 3 in the Supplementary Material http://www.atmos-chem-phys.net/9/2751/ 2009/acp-9-2751-2009-supplement.pdf), which is produced after the $\mathrm{NO}_{3}$-addition to propene. It is worth noting that one alkyl nitrate from the OH-pathway (LISOPACNO3) is produced in the permutation reaction of NISOPO2 in the $\mathrm{NO}_{3}$-pathway as well (see Table 3 in the Supplementary Material http://www.atmos-chem-phys.net/9/2751/ 2009/acp-9-2751-2009-supplement.pdf). The chemistry of the alkyl nitrates in MCM and MIM2 is treated in a simplified manner. However, it is easily extendable, for example including ozonolysis reactions as in two recent models (Horowitz et al., 2007; Giacopelli et al., 2005).

The mixing ratios of the MIM2 $\mathrm{C}_{5}$-alkyl nitrates are shown in Fig. 8 in the three different $\mathrm{NO}_{\mathrm{x}}$ scenarios. It can be seen that the relative distributions of the alkyl nitrates from the two pathways changes drastically with $\mathrm{NO}_{\mathrm{x}}$ levels. In the low- $\mathrm{NO}_{\mathrm{x}}$ scenario the $\mathrm{C}_{5}$-alkyl nitrates from the $\mathrm{OH}$ pathway always dominate with respect to the ones from the $\mathrm{NO}_{3}$-pathway. In fact, they account for between $55-75 \%$ of the total $\mathrm{C}_{5}$-alkyl nitrates. As the system changes towards the high- $\mathrm{NO}_{\mathrm{x}}$ regimes, the diurnal cycles of $\mathrm{C}_{5}$-alkyl nitrates become very pronounced. Under such conditions the $\mathrm{C}_{5}$-alkyl nitrates from the $\mathrm{NO}_{3}$-pathway start to dominate during nighttime, accounting for about $90 \%$ of the total nitrates. In two recent studies using very reduced isoprene oxidation mechanisms, it was estimated that the total fraction of the $\mathrm{C}_{5}$-alkyl nitrates produced at night ranges from $50 \%$ to more than 60\% (von Kuhlmann et al., 2004; Horowitz et al., 2007). When MIM2 is implemented in a global atmospheric model, the $\mathrm{C}_{5}$-alkyl nitrates from the two pathways are produced in roughly the same amounts (see Sect. 4). MIM considers only one $\mathrm{C}_{5}$-alkyl nitrate (ISON) produced by both 

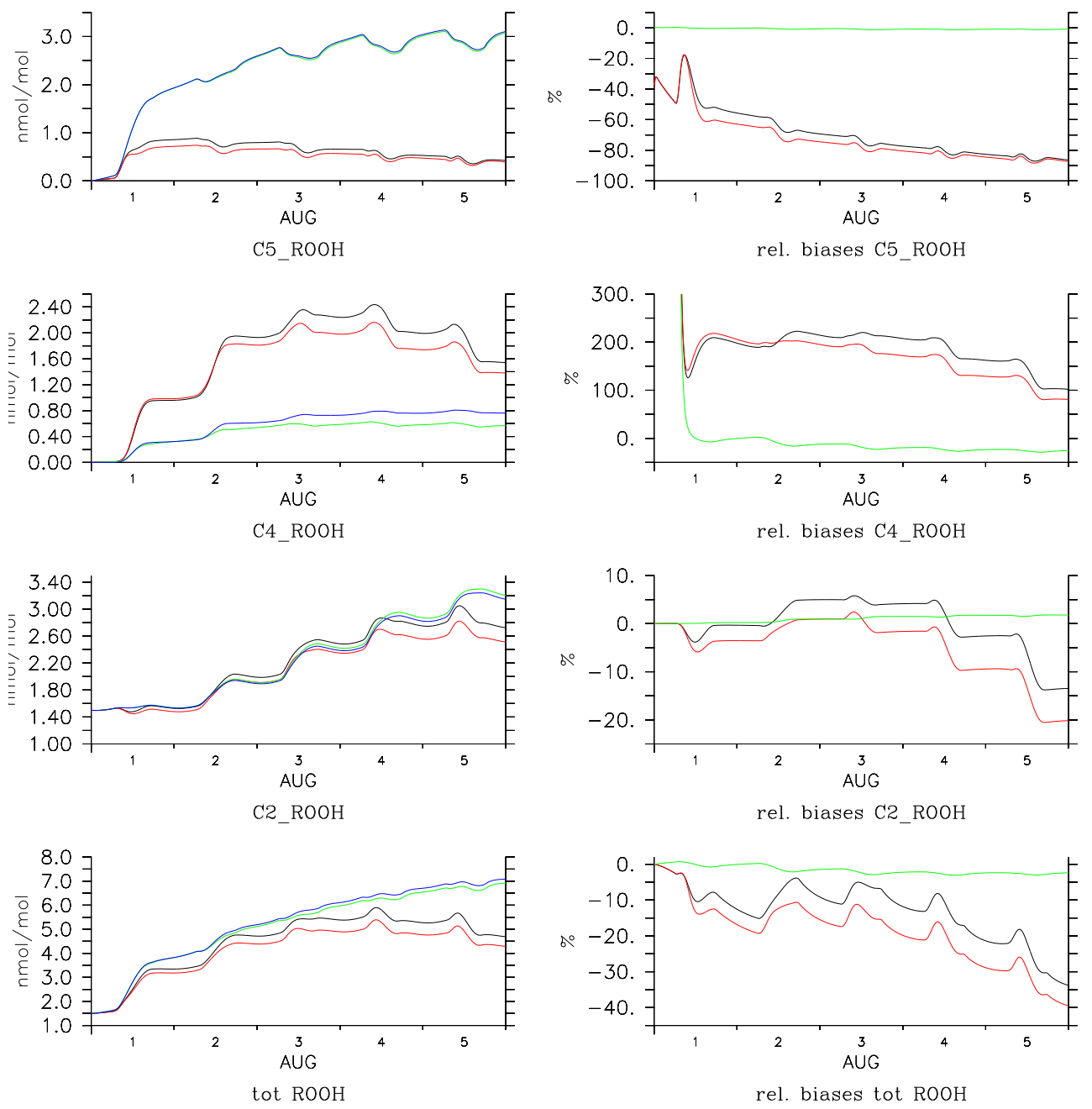

Fig. 13. Organic peroxides other than $\mathrm{CH}_{3} \mathrm{OOH}$ for all four mechanisms in this study under mid- $\mathrm{NO}_{\mathrm{x}}$ conditions. In all the plots the actual mixing ratios of each species are presented with MIMvK (black line), original MIM (red line), MIM2 (green line) and MCM (blue line). $\mathrm{C}_{3}$-peroxides are not shown because MIM and MIMvK do not have any.

the $\mathrm{OH}$ - and $\mathrm{NO}_{3}$-pathways. The peroxy radical that should result from the addition of $\mathrm{NO}_{3}$ to isoprene is assumed to go directly into ISON, which has the properties of a longlived species. In fact, this lumped species in MIM reacts with $\mathrm{OH}$, yielding hydroxyacetone and nitroxyacetaldehyde (called NALD in MIM). The rate constant assigned to this reaction is $k=1.3 \cdot 10^{-11} \mathrm{~cm}^{3}$ molecule ${ }^{-1} \mathrm{~s}^{-1}$, being a factor between 3 and 9 lower than the actual rate constants for the single isomers that ISON represents. The rate constant for that reaction is artificial and was used by Pöschl et al. (2000) to strongly tune MIM to the MCM results. Moreover, the species NALD, and called $\mathrm{NO}_{3} \mathrm{CH}_{2} \mathrm{CHO}$ in MCM, is actually a product of 1,3-butadiene and 2-methylbut-3-en-2-ol oxidation. Furthermore, we note that in such a reaction there is no release of $\mathrm{NO}_{2}$ as for the alkyl nitrates resulting from the OH-pathway. We note that the treatment of the alkyl ni- trates in MCM is also to an extent simplified. Overall this causes MIM to accumulate too much nitrogen in the alkyl nitrates (relative bias up to $900 \%$ in high- $\mathrm{NO}_{\mathrm{x}}$ scenario), delaying considerably the release of $\mathrm{NO}_{2}$ down the oxidation chain. Since MIM2 considers eight alkyl nitrate species, it is a very appropriate tool to constrain the chemistry of alkyl nitrates with field data and an atmospheric chemistry model like in Horowitz et al. (2007). In that study their model was found to fit the field data the best with a $4 \%$ yield of alkyl nitrates from the reaction of isoprene peroxy radicals with NO. By contrast, MCM was found to match chamber data experiments with an average yield of $10 \%$ from such reactions (Pinho et al., 2005). The MIM2 relative biases for NOA are very small as well. By contrast, we show in Figs. 911 MIM computing large relative biases either for the alkyl nitrates or for NOA (compared to NALD from MIM). The 

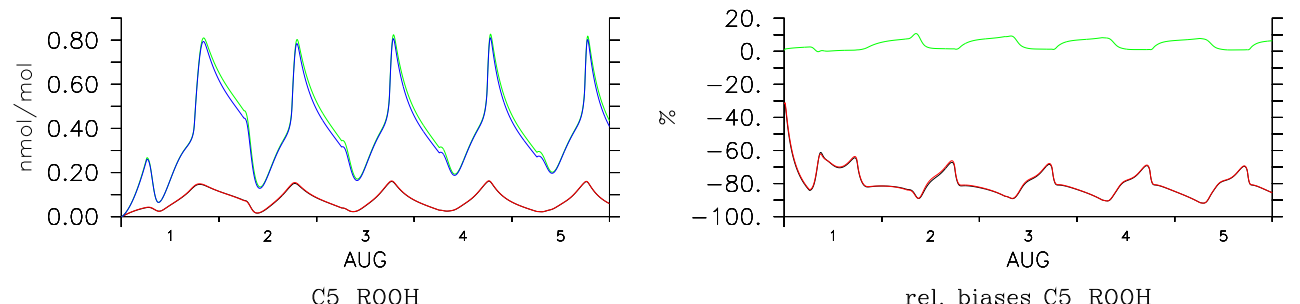

rel. biases C5_ROOH
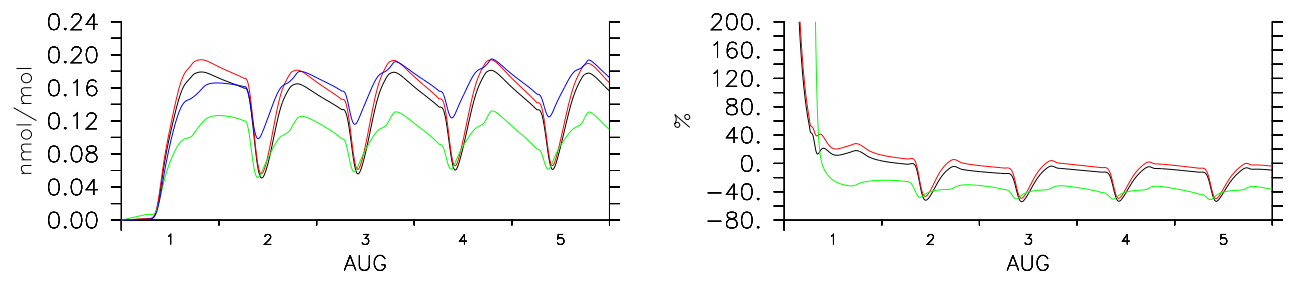

C4_ROOH

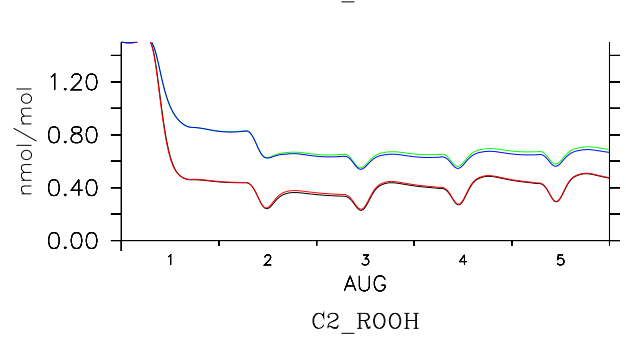

rel. biases $\mathrm{C}_{-} \mathrm{ROOH}_{\mathrm{H}}$
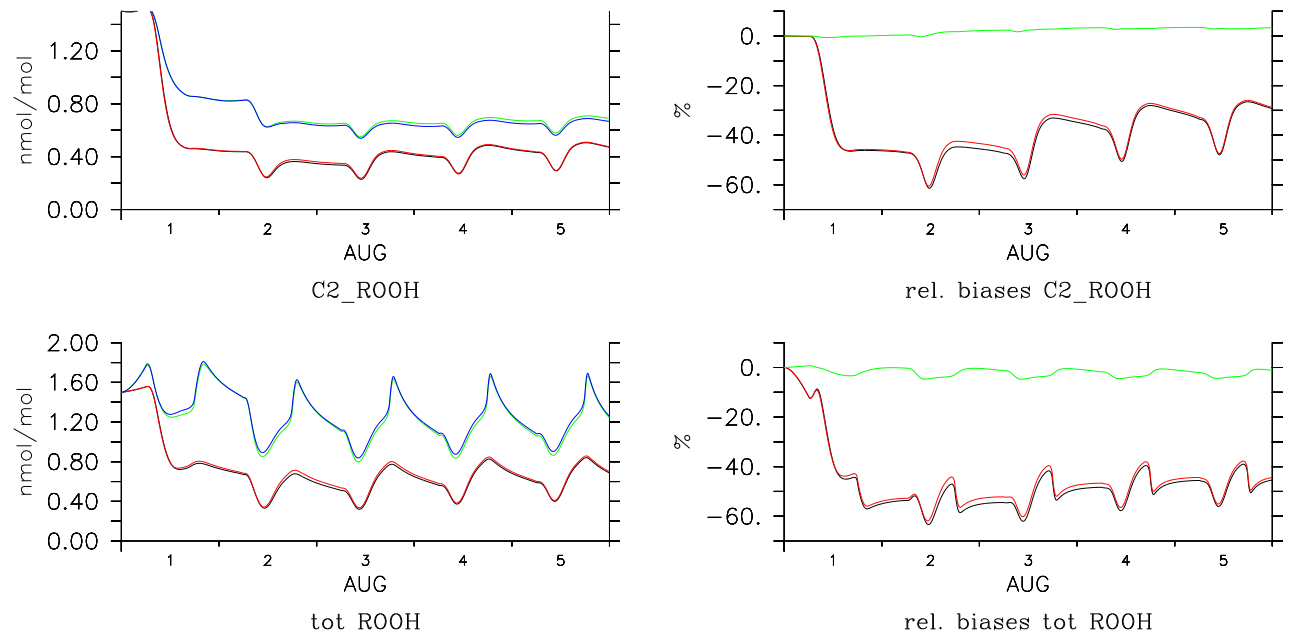

rel. biases tot $\mathrm{ROOH}$

Fig. 14. Organic peroxides other than $\mathrm{CH}_{3} \mathrm{OOH}$ for all four mechanisms in this study under high- $\mathrm{NO}_{\mathrm{x}}$ conditions. In all the plots the actual mixing ratios of each species are presented with MIMvK (black line), original MIM (red line), MIM2 (green line) and MCM (blue line). $\mathrm{C}_{3}$-peroxides are not shown because MIM and MIMvK do not have any.

chemistry and the physical properties, such as solubility, of the $\mathrm{C}_{5}$-alkyl nitrates and NOA are rather different, with the former ones having a double bond and an hydroxy group and the latter with none of these. Hence, the interplay between the chemistry, deposition and transport is expected to be non-negligible in a 3-D atmospheric chemistry model.

\subsubsection{Peroxy acyl nitrates}

PAN and its homologues have the general formula $\mathrm{RC}(\mathrm{O}) \mathrm{OONO}_{2}$, and the isoprene mechanism in MCM considers 11 of them. MIM2 considers four peroxy acyl nitrates. In the low- $\mathrm{NO}_{\mathrm{x}}$ scenario the MIM2 relative bias for the total peroxy acyl nitrates is in the 5\% range, while in the other two $\mathrm{NO}_{\mathrm{x}}$ scenarios it reaches values as low as $-15 \%$ (Figs. 911). In all cases the largest deviations from the MCM results occur during nighttime when temperatures favour the forma- tion of $\mathrm{RC}(\mathrm{O}) \mathrm{OONO} 2$. This indicates a lower capacity of the reduced mechanism to store nitrogen in this reservoir.

\section{7 $\mathbf{C}_{2}-\mathbf{C}_{5}$ peroxides}

Comparisons of the higher organic peroxides from the reduced mechanisms are shown for all $\mathrm{NO}_{\mathrm{x}}$ scenarios considered here (see Figs. 12-14). Large MIM2 biases are computed only for the high- $\mathrm{NO}_{\mathrm{x}}$ conditions. They originate from the nighttime chemistry that is simplified in MIM2, neglecting an important sink for the peroxy radicals, namely its reaction with $\mathrm{NO}_{3}$ radicals (see Sect. 3.5.2). Clearly the biases grow during nighttime when $\mathrm{NO}_{3}$ mixing ratios are nonnegligible, while during daytime they decrease substantially. 

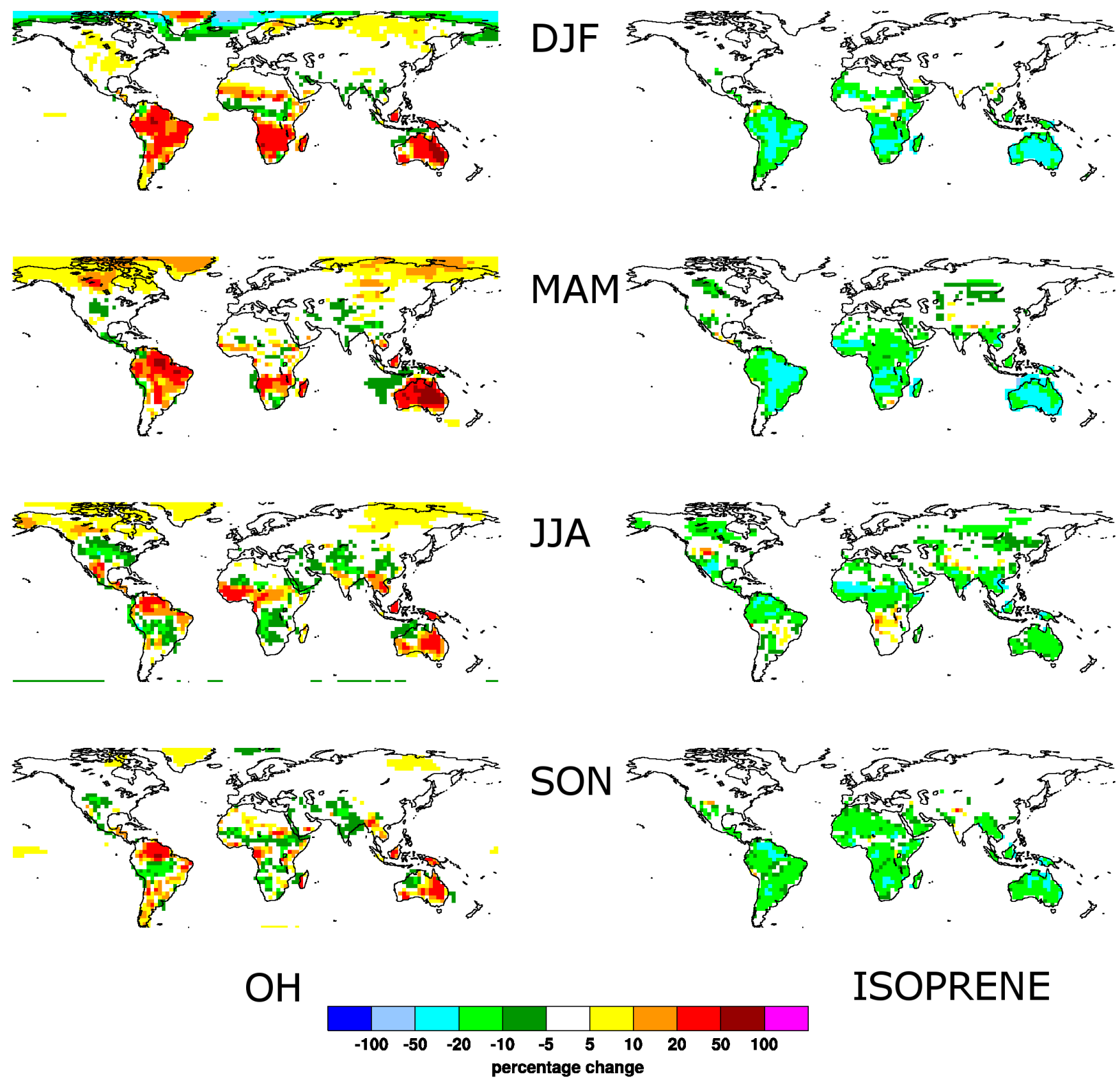

\section{ISOPRENE}

Fig. 15. Seasonal relative change MIM2-MIMvK for $\mathrm{OH}$ (left panel) and isoprene (right panel).

\section{Impact on the global scale}

\subsection{Implementation in a global model}

The focus of this section is on the differences between 3D simulations with MIM2 and with the mechanism referred to here as MIMvK, used in a recently established global atmospheric chemistry model (Jöckel et al., 2006). The total isoprene emission in the simulations for the year 2005 was $566.7 \mathrm{Tg} / \mathrm{yr}$ of isoprene, equivalent to $500 \mathrm{Tg}(\mathrm{C}) / \mathrm{yr}$. The model setup is described in more detail in Butler et al. (2008). All the tested mechanisms were budgeted and the product yields per molecule of isoprene estimated. The contribution of each pathway to the isoprene oxidation was calculated to be $84 \%$ for $\mathrm{OH}, 11 \%$ for $\mathrm{O}_{3}$ and $5 \%$ for $\mathrm{NO}_{3}$, globally. Pfister et al. (2008) estimated similar contributions being $80 \%$ for $\mathrm{OH}, 15 \%$ for $\mathrm{O}_{3}$ and $5 \%$ for $\mathrm{NO}_{3}$. The product yields of isoprene in global models are subject to uncertainties due to assumptions regarding dry and wet deposition of the relative intermediates, as well as other contributing 
(MIM2mod-MIM2)/MIM2

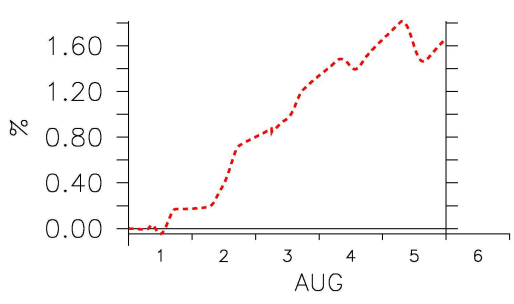

03
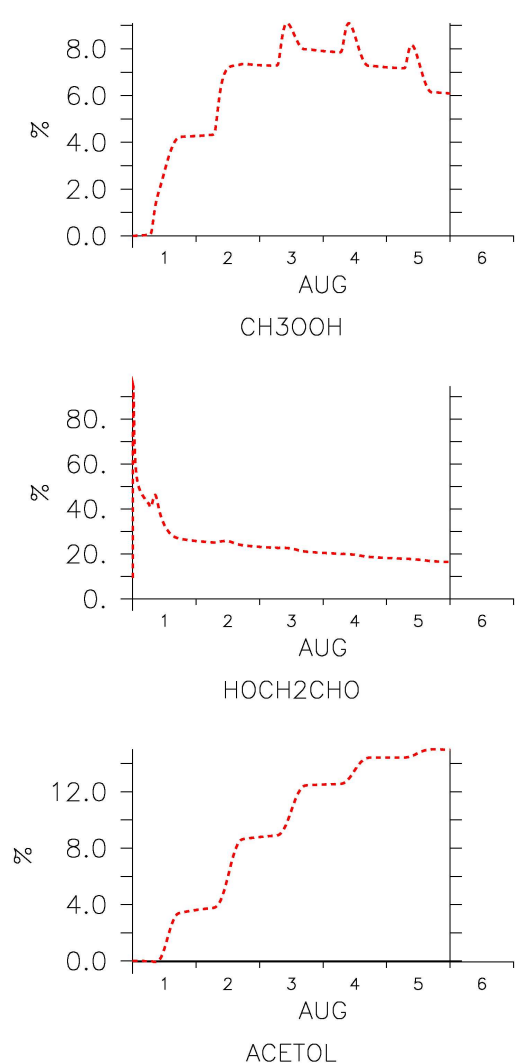

ACETOL

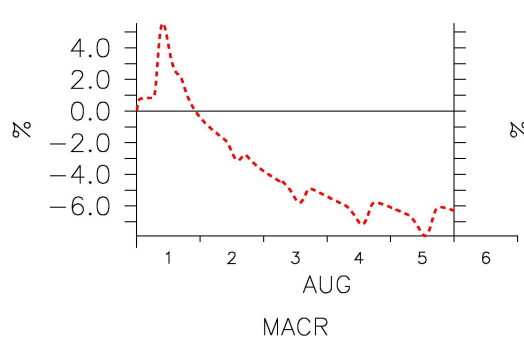

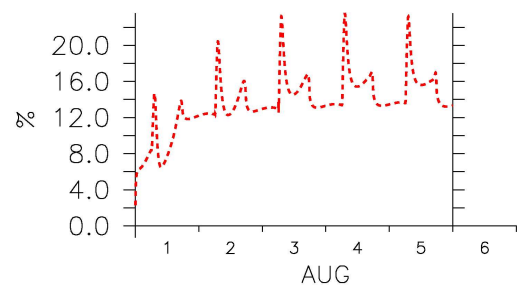

$\mathrm{OH}$

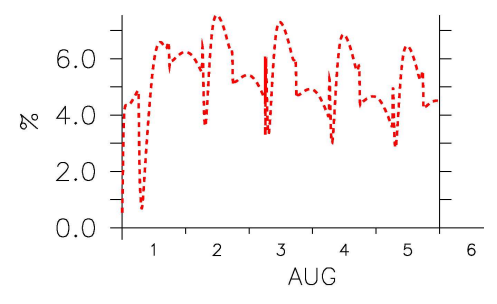

$\mathrm{HO} 2$

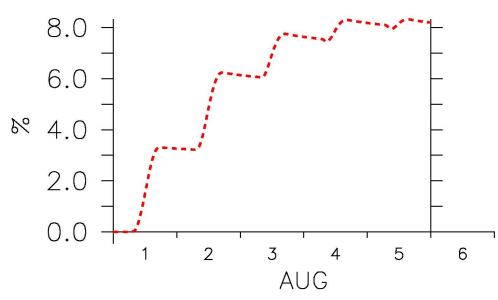

$\mathrm{H} 2 \mathrm{O} 2$
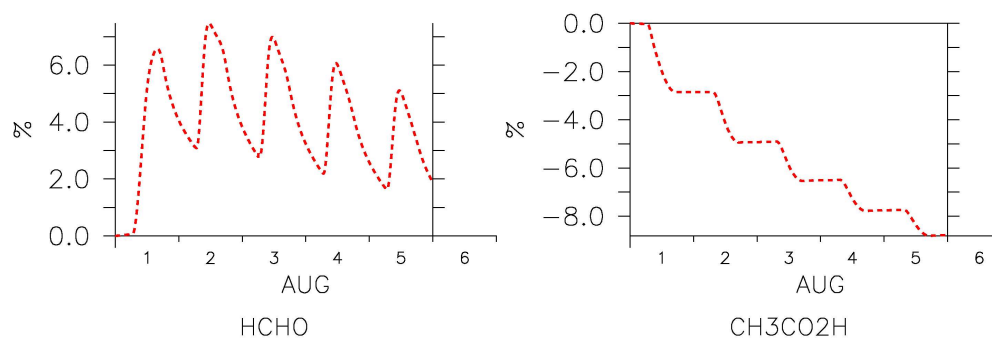

$\mathrm{CH} 3 \mathrm{CO} 2 \mathrm{H}$
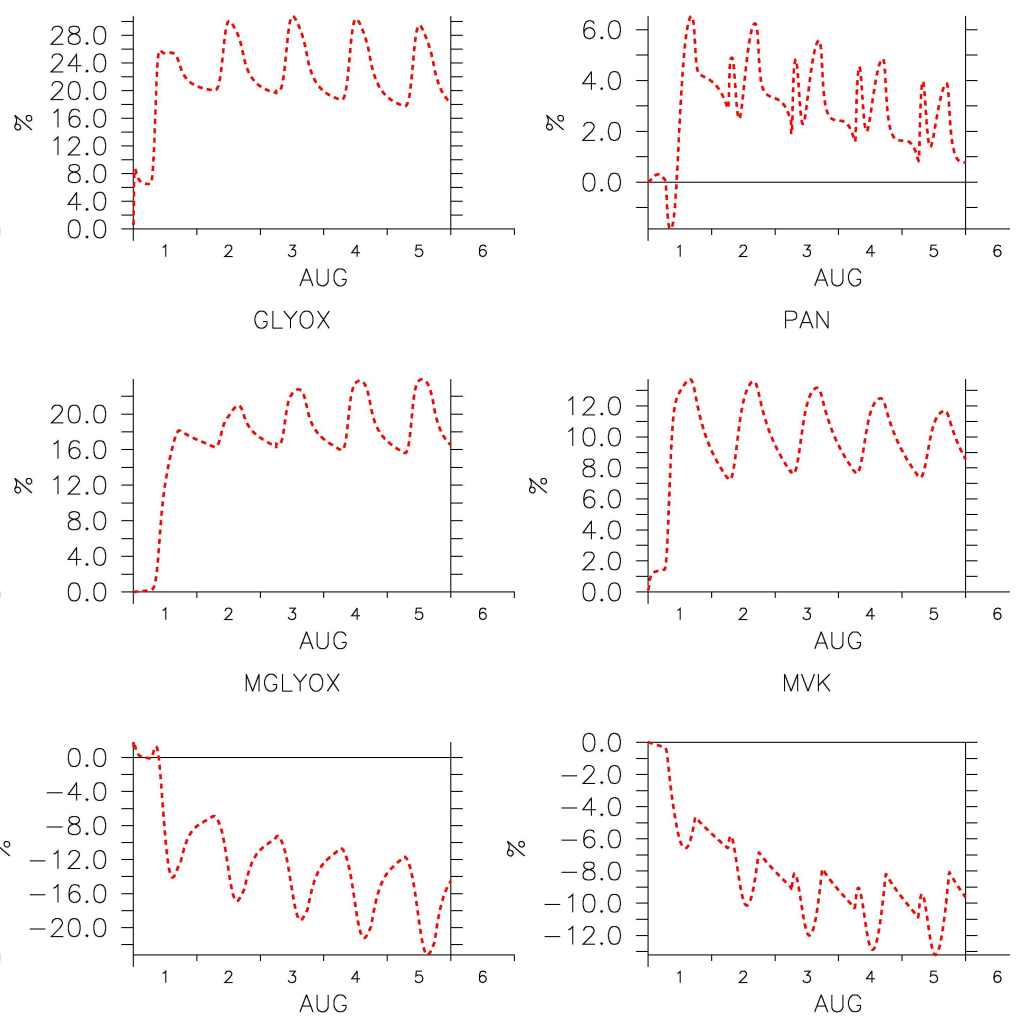

C5 alkyl nitrates

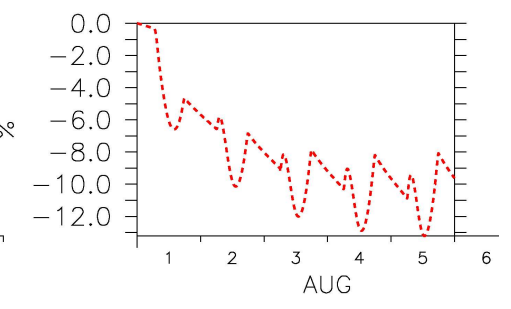

$\mathrm{C} 5 \mathrm{H} 8$

Fig. 16. Relative differences of the modified MIM2 for some major species under the low- $\mathrm{NO}_{\mathrm{x}}$ scenario. 
factors such as emissions and transport. Note that a few minor updates to MIM2 were made after this global run was completed, but these should be have negligible effects on the results presented here in this section.

\section{2 $\mathrm{OH}$ and isoprene}

The seasonal relative differences for $\mathrm{OH}$ and isoprene between the MIM2 and MIMvK isoprene mechanisms are presented in Fig. 15. The reduction in isoprene mixing ratios in MIM2 is expected to improve the model-measurement agreement over a region like Amazonia, in which models have traditionally overestimated isoprene mixing ratios by about a factor of 3 (von Kuhlmann et al., 2004). For this reason such models have been implemented in the past with isoprene emission strengths in the range $215-350 \mathrm{Tg}(\mathrm{C}) / \mathrm{yr}$, well below the range of $424-530 \mathrm{Tg}(\mathrm{C}) / \mathrm{yr}$ calculated by different models (Guenther et al., 1995, 2006; Lathière et al., 2006; Müller et al., 2008). The overall increase in $\mathrm{OH}$ and the decrease in isoprene mixing ratios, however, are not enough to match the observations which were made during the GABRIEL campaign (Lelieveld et al., 2008). A more in-depth discussion of the model-measurement comparison during this campaign for $\mathrm{OH}$, isoprene and many other intermediates is presented in Butler et al. (2008).

\subsection{New species}

There are many important species in MIM2 that are either new (compared to MIM) or not lumped anymore. We discuss the relevance of the chemical production of three new species with respect to their atmospheric budgets.

\subsubsection{Glyoxal}

The total yield of glyoxal in our 3-D simulation is estimated to be $7.0 \%$ and results in a chemical production only from isoprene oxidation of $33.83 \mathrm{Tg} / \mathrm{yr}$. Recently, Myriokefalitakis et al. (2008) calculated a total global production of $56 \mathrm{Tg} / \mathrm{yr}$, of which $39.2 \mathrm{Tg} / \mathrm{yr}(70 \%)$ is from the oxidation of biogenic VOC. The main contributors were isoprene and monoterpenes with global annual emissions of $501 \mathrm{Tg} / \mathrm{yr}$ and $244 \mathrm{Tg} / \mathrm{yr}$, respectively. However, satellite retrievals show that global atmospheric chemistry models underestimate the glyoxal annual mean total column where terpene emissions are the strongest (Myriokefalitakis et al., 2008; Wittrock et al., 2006).

\subsubsection{Propene}

Propene $\left(\mathrm{CH}_{2}=\mathrm{CHCH}_{3}\right)$ is produced with yields of $12.75 \%$ from ozonolysis of isoprene and of $50 \%$ from the photolysis of MVK (Atkinson et al., 2006). In MCM and MIM2 its yield from MVK photolysis is $60 \%$. In a recent study by Pozzer et al. (2007) the parameterized emission from vegetation was $2.15 \mathrm{Tg} / \mathrm{yr}$ with all off-line sources amounting to
$9.94 \mathrm{Tg} / \mathrm{y}$ (A. Pozzer, personal communication, 2008). The total yield of propene in the 3-D simulation is estimated to be $2.7 \%$, resulting in a chemical production of $9.451 \mathrm{Tg} / \mathrm{yr}$. Moreover, judging from Pozzer et al. (2007), this chemical source of propene is expected to substantially improve the representation of its diurnal cycle and its vertical distribution compared to observations.

\subsubsection{Acetaldehyde}

The total yield of acetaldehyde is $2 \%$ and the chemical production from isoprene oxidation amounts to $7.33 \mathrm{Tg} / \mathrm{yr}$. It is produced in the ozonolysis of MVK and the oxidation of propene. According to our simulations isoprene oxidation can account for about 5 to $10 \%$ of the large missing global source of acetaldehyde of $80-160 \mathrm{Tg} / \mathrm{yr}$ inferred by Singh et al. (2001).

\section{Incorporation of new experimental results}

Lelieveld et al. (2008) first proposed that the current understanding of isoprene chemistry under low- $\mathrm{NO}_{\mathrm{x}}$ conditions is not well understood yet. To date, $\mathrm{NO}_{\mathrm{x}}$-free experimental studies of isoprene reactions have been sparse and difficult. In fact, under these conditions the major oxidation products are the hydroperoxides that have low volatilities and are labile. The current MCM isoprene chemistry reflects the experimental knowledge that was available at the time of Jenkin et al. (1998), and has not been significantly updated since then. Therefore, we show here the impact of some recent experimental results on a simulation under the low- $\mathrm{NO}_{\mathrm{x}}$ scenario. This highlights one of the major advancements of MIM2: unlike in MIM (and other highly lumped reduced mechanisms), the implementation of such changes in MIM2 is very straightforward.

The modifications consist of:

(1) elimination of the species MVKOH (1-hydroxybut-3en-2-one), since Benkelberg et al. (2000) found no evidence for its formation from isoprene oxidation.

(2) implementation of the degradation of the methyl vinyl radical from MACR oxidation (Orlando et al., 1999).

(3) adoption of the product yields for the first peroxy radicals of isoprene as recently estimated by Paulot et al. (2009). Two minor isomers yield MVK and MACR as products. Therefore, their yields are added to the those of ISOPBO2 and ISOPDO2.

(4) adoption of the corresponding (see point 3) alkyl nitrate yields from the $\mathrm{RO}_{2}+\mathrm{NO}$ reactions. For the externally and internally double bonded isomers the yields are 0.057 and 0.24 , respectively.

(5) inclusion of the new results on the $\mathrm{RO}_{2}+\mathrm{HO}_{2}$ reactions for which $\mathrm{OH}$ has been found to often be a product (Hasson et al., 2004; Jenkin et al., 2007; Dillon and Crowley, 2008). For the acyl and $\beta$-keto peroxy radicals we used $\mathrm{OH}$ 
yields of 0.50 and 0.15 , respectively. These yields are taken from Dillon and Crowley (2008) which is the only study in which $\mathrm{OH}$ was detected. The branching ratios of the radical terminating channels were then re-scaled so that the total yield was unity.

The results of the modified MIM2 are shown in Fig. 16. For most species the deviations from MIM2 become significant after two days. An increase in the $\mathrm{OH}$ concentration of about $15 \%$ at noon appears to be the result of the non-radical terminating branches of the $\mathrm{RO} 2+\mathrm{HO}_{2}$ reactions. The isoprene mixing ratio decreases by roughly the same amount. Hydroperoxides like $\mathrm{H}_{2} \mathrm{O}_{2}$ and $\mathrm{CH}_{3} \mathrm{OOH}$ increase by about $8 \% . \mathrm{O}_{3}$ is found to change to a mall extent (1-2\%). Interestingly, the mixing ratios of the two dicarbonyls, glyoxal and methyl glyoxal, increase by more than $20 \%$. This should significantly reduce the underestimation of glyoxal over pristine tropical forest by models (Myriokefalitakis et al., 2008). The MVK mixing ratio increases by more the $10 \%$ while MACR decreases by about $8 \%$. The average alkyl nitrate yield for the $\mathrm{RO}_{2}+\mathrm{NO}$ reactions of the $\mathrm{OH}$-pathway is slightly increased from $10 \%$ to about $11 \%$. However, the total mixing ratio of the alkyl nitrates with 5 carbon atoms decreases by more than $15 \%$ already after the second day. These changes are mainly due to increases in $\mathrm{OH}$ mixing ratios.

Though the changes in species abundances indicated above are significant, they are are still insufficient to explain the high $\mathrm{HO}_{\mathrm{x}}$ levels measured during the GABRIEL campaign (Lelieveld et al., 2008). New insights in the low- $\mathrm{NO}_{\mathrm{x}}$ chemistry of isoprene are needed. They will likely involve unknown decomposition pathways of peroxy radicals and hydroperoxides from isoprene oxidation.

\section{Conclusions}

A set of principles for the development of reduced mechanisms has been proposed. The application of these principles has led to the development of an isoprene oxidation mechanism, called MIM2, of intermediate size for regional and global atmospheric models. MIM2 has been described and evaluated against the MCM in a box model representative of a tropical continental boundary layer. MIM2 is mass conserving with respect to carbon, including $\mathrm{CO}_{2}$. Compared to its predecessor MIM, MIM2 offers several improvements, as summarized below.

The mechanism was found to compute small average relative biases $(<6 \%)$ for most of the intermediate species under all $\mathrm{NO}_{\mathrm{x}}$ regimes studied (see Table 3). For instance, this is the case for $\mathrm{C}_{5}$-alkyl nitrates, hydroperoxides and diols. The $\mathrm{C}_{5}$-hydroperoxides are suggested to be precursors for organic aerosol nucleation and growth from isoprene oxidation (Kroll et al., 2006) and the $\mathrm{C}_{5}$-diols are precursors of tetrols found recently in aerosols (Claeys et al., 2004; Böge et al., 2006). MIM2 (MIM) was found to compute relative biases for formic and acetic acid, which are important components of the gas and aqueous phase of the atmosphere (Chebbi and Carlier, 1996), reaching about $-10 \%(+300 \%)$ and $+10 \%$ $(-40 \%)$, respectively. HCHO nocturnal production is close to the rate in the MCM with the average relative bias being less than $1 \%$. Chemical production of $\mathrm{CH}_{3} \mathrm{OH}$ has been improved substantially under all $\mathrm{NO}_{\mathrm{x}}$ conditions. The representation of the organic nitrogen has been improved remarkably due to the consideration of eight alkyl nitrates $\left(\mathrm{RONO}_{2}\right)$ and four peroxy acyl nitrates $\left(\mathrm{RC}(\mathrm{O}) \mathrm{OONO}_{2}\right)$, causing the $\mathrm{NO}_{\mathrm{x}}$ relative bias to be always less than $10 \%$. MIM2 has been implemented in a global atmospheric chemistry model and compared to the modified version of MIM, here referred as MIMvK. MIM2 helps global models accommodate higher isoprene emissions without computing unrealistically high isoprene mixing ratios (Butler et al., 2008). Amongst the new species present in MIM2, the global chemical production of important species like acetaldehyde, propene and glyoxal is found to be 7.3, 9.5 and $33.8 \mathrm{Tg} / \mathrm{yr}$, respectively. Among the other new species it is worth mentioning glycolaldehyde, $\alpha$ nitrooxy acetone, two more peroxy acyl nitrates, as well as, MVK and MACR which were lumped in the previous MIM version. The overall improvement in the computation of key atmospheric species and of the isoprene oxidation intermediates is shown to be substantial. Along with enabling regional and global models to easily incorporate new experimental results on the chemistry of organic species, MIM2 represents a step forward in modelling the atmospheric composition.

Acknowledgements. The authors thank M. E. Jenkin and U. Pöschl for valuable discussions. D. Taraborrelli acknowledges the International Max Planck Research School (IMPRS) for financial support.

The service charges for this open access publication have been covered by the Max Planck Society.

Edited by: R. Cohen

\section{References}

Aschmann, S. M. and Atkinson, R.: Formation yields of methyl vinyl ketone and methacrolein from the gas-phase reaction of $\mathrm{O}_{3}$ with isoprene, Environ. Sci. Technol., 28, 1539-1542, 1994.

Atkinson, R. and Arey, J.: Atmospheric Degradation of Volatile Organic Compounds, Chem. Rev., 103, 12, 4605-4638, 2003a.

Atkinson, R. and Arey, J.: Gas-phase tropospheric chemistry of biogenic volatile organic compounds: a review, Atmos. Environ., 2, S197-S219, 2003b.

Atkinson, R., Aschmann, S. M., Arey, J., and Shorees, B.: Formation of $\mathrm{OH}$ radicals in the gas-phase reaction of $\mathrm{O}_{3}$ with a series of terpenes, J. Geophys. Res., 97, 6065-6073, 1992.

Atkinson, R., Arey, J., Aschmann, S. M., and Tuazon, E. C.: Formation of $\mathrm{O}(3 \mathrm{P})$ atoms and epoxides from the gas-phase reaction of $\mathrm{O}_{3}$ with isoprene, Res. Chem. Intermediat., 20, 385-394, 1994.

Atkinson, R., Baulch, D. L., Cox, R. A., Crowley, J. N., Hampson, R. F., Hynes, R. G., Jenkin, M. E., Rossi, M. J., and Troe, J.: 
Evaluated kinetic and photochemical data for atmospheric chemistry: Volume II gas phase reactions of organic species, Atmos. Chem. Phys., 6, 3625-4055, 2006,

http://www.atmos-chem-phys.net/6/3625/2006/.

Benkelberg, H. J., Böge, O., Seuwen, R., and Warneck, P.: Product distributions from the $\mathrm{OH}$ radical-induced oxidation of but1-ene, methyl-substituted but-1-enes and isoprene in $\mathrm{NO}_{\mathrm{x}}$-free air, Phys. Chem. Chem. Phys., 2, 4029-4039, 2000.

Biesenthal, T. A., Bottenheim, J. W., Shepson, P. B., Li, S.-M., and Brickell, P. C.: The chemistry of biogenic hydrocarbons at a rural site in eastern Canada, J. Geophys. Res., 103, 25487-25498, 1998.

Böge, O., Miao, Y., Plewka, A., and Herrmann, H.: Formation of secondary organic particle phase compounds from isoprene gasphase oxidation products: An aerosol chamber and field study, Atmos. Environ., 40, 2501-2509, 2006.

Brasseur, G. P., Hauglustaine, D. A., Walters, S., Rasch, P. J., Müller, J.-F., Granier, C., and Tie, X. X.: MOZART, a global chemical transport model for ozone and related chemical tracers 1. Model description, J. Geophys. Res., 103, 28265-28290, 1998.

Butler, T. M., Taraborrelli, D., Brühl, C., Fischer, H., Harder, H., Lawrence, M. G., Martinez, M., Williams, J., and Lelieveld, J.: Improved simulation of isoprene oxidation chemistry with the ECHAM5/MESSy chemistry-climate model: Lessons from the GABRIEL airborne field campaign, Atmos. Chem. Phys., 8, 4529-4546, 2008, http://www.atmos-chem-phys.net/8/4529/2008/.

Carlton, A. G., Turpin, B. J., Altieri, K. E., Seitzinger, S., Reff, A., Lime, H.-J., and Ervens, B.: Atmospheric oxalic acid and SOA production from glyoxal: Results of aqueous photooxidation experiments, Atmos. Environ., 41, 7588-7602, 2007.

Carslaw, N., Creasey, D. J., Heard, D. E., Lewis, A. C., McQuaid, J. B., Pilling, M. J., Monks, P. S., Bandy, B. J., and Penkett, S. A.: Modeling $\mathrm{OH}, \mathrm{HO}_{2}$, and $\mathrm{RO}_{2}$ radicals in the marine boundary layer - 1 . Model construction and comparison with field measurements, J. Geophys. Res., 104, D23, 30241-30255, 1999a.

Carslaw, N., Jacobs, P. J., and Pilling, M. J.: Modeling OH, HO2, and $\mathrm{RO} 2$ radicals in the marine boundary layer 2. Mechanism reduction and uncertainty analysis, J. Geophys. Res., 104, D23, 30257-30273, 1999b.

Carslaw, N., Harrison, D., Heard, D. E., Hunter, M. C., Jacobs, P. J., Jenkin, M. E., Lee, J. D., Lewis, A. C., Pilling, M. J., Saunders, S. M., and Seakins, P. W.: $\mathrm{OH}$ and $\mathrm{HO}_{2}$ radical chemistry in a forested region of north-western Greece, Atmos. Environ., 35, 4725-4737, 2001.

Carter, W. P. L.: Documentation of the SAPRC-99 chemical mechanism for VOC reactivity assessment, Final report to california air resources board contract 92-329 and contract 95-308, Air polluiton research center and college of engineering center for environmental research and technology University of California, Riverside, CA, 2000.

Carter, W. P. L. and Atkinson, R.: Development and evaluation of a detailed mechanism for atmospheric reactions of isoprene and $\mathrm{NO}_{\mathrm{x}}$, Int. J. Chem. Kinetics, 28, 497-530, 1996.

Chebbi, A. and Carlier, P.: Carboxylic acids in the troposphere, occurrence, sources and sinks: a review, Atmos. Environ., 30, 4233-4249, 1996.

Chen, X., Hulbert, D., and Shepson, P. B.: Measurement of the organic nitrate yield from $\mathrm{OH}$ reaction with isoprene, J. Geophys. Res., 103, 25563-25568, 1998.

Chen, Z. M., Wang, H. L., Zhu, L. H., Wang, C. X., Jie, C. Y., and Hua, W.: Aqueous-phase ozonolysis of methacrolein and mehtyl vinyl ketone: a potentially important source of aqueous oxidants, Atmos. Chem. Phys., 8, 2255-2265, 2008, http://www.atmos-chem-phys.net/8/2255/2008/.

Claeys, M., Graham, B., Vas, G., Wang, W., Vermeylen, R., Pashynska, V., Cafmeyer, J., Guyon, P., Andreae, M. O., Artaxo, P., and Maenhaut, W.: Formation of Secondary Organic Aerosols Through Photooxidation of Isoprene, Science, 303, 1173-1176, 2004.

de Gouw, J. and Warneke, C.: Measurements of volatile organic compounds in the Earth's atmosphere using proton-transferreaction mass spectrometry, Mass Spectrom. Rev., 26, 223-257, 2007.

Dillon, T. J. and Crowley, J. N.: Direct detection of $\mathrm{OH}$ formation in the reactions of $\mathrm{HO}_{2}$ with $\mathrm{CH}_{3} \mathrm{C}(\mathrm{O}) \mathrm{O}_{2}$ and other substituted peroxy radicals, Atmos. Chem. Phys., 8, 4877-4889, 2008, http://www.atmos-chem-phys.net/8/4877/2008/.

Emmons, L. K., Carroll, M. A., Hauglustaine, D. A., Brasseur, G. P., Atherton, C., Penner, J., Sillman, S., Levy, H., Rohrer, F., Wauben, W. M. F., Velthoven, P. F. J. V., Wang, Y., Jacob, D., Bakwin, P., Dickerson, R., Doddridge, B., Gerbig, C., Honrath, R., Hubler, G., Jaffe, D., Kondo, Y., Munger, J. W., Torres, A., and Volz-Thomas, A.: Climatologies of $\mathrm{NO}_{\mathrm{x}}$ and $\mathrm{NO}_{\mathrm{y}}$ : A comparison of data and models, Atmos. Environ., 31, 1851-1904, 1997.

Fan, J. and Zhang, R.: Atmospheric oxidation mechanism of isoprene, Environ. Chem., 1, 140-149, 2004.

Fehsenfeld, F., Calvert, J., Fall, R., Goldan, P., Guenther, A. B., Hewitt, C. N., Lamb, B., Liu, S., Trainer, M., Westberg, H., and Zimmerman, P.: Emissions of volatile organic compounds from vegetation and the implications for atmospheric chemistry, Global Biogeochem. Cy., 6, 389-430, 1992.

Folberth, G. A., Hauglustaine, D. A., Lathière, J., and Brocheton, F.: Interactive chemistry in the Laboratoire de Météorologie Dynamique general circulation model: model description and impact analysis of biogenic hydrocarbons on tropospheric chemistry, Atmos. Chem. Phys., 34, 2273-2319, 2006, http://www.atmos-chem-phys.net/34/2273/2006/.

Geiger, H., Barnes, I., Bejan, I., Benter, T., and Spittler, M.: The tropospheric degradation of isoprene: an updated module for the regional atmospheric chemistry mechanism, Atmos. Environ., 37, 1503-1519, 2003.

Giacopelli, P., Ford, K., Espada, C., and Shepson, P. B.: Comparison of the measured and simulated isoprene nitrate distributions above a forest canopy, J. Geophys. Res., 110, D01304, doi:10.1029/2004JD005123, 2005.

Grosjean, D., Williams, E. L., and Grosjean, E.: Atmospheric chemistry of isoprene and its carbonyl products, Environ. Sci. Technol., 27, 830-840, 1993.

Guenther, A., Hewitt, C. N., Erickson, D., Fall, R., Geron, C., Graedel, T., Harley, P., Klinger, L., Lerdau, M., McKay, W. A., Pierce, T., Scholes, B., Steinbrecher, R., Tallamraju, R., Taylor, J., and Zimmerman, P.: A global model of natural volatile organic compound emissions, J. Geophys. Res., 100, 8873-8892, 1995.

Guenther, A., Karl, T., Harley, P., Wiedinmyer, C., Palmer, P. I., 
and Geron, C.: Estimates of global terrestrial isoprene emissions using MEGAN (Model of Emissions of Gases and Aerosols from Nature), Atmos. Chem. Phys., 6, 3181-3210, 2006, http://www.atmos-chem-phys.net/6/3181/2006/.

Gutbrod, R., Meyer, S., Rahman, M. M., and Schindler, R. N.: On the use of $\mathrm{CO}$ as scavenger for $\mathrm{OH}$ radicals in the ozonolysis of simple alkenes and isoprene, Int. J. Chem. Kinetics, 29, 717-723, 1997.

Hasson, A. S., Tyndall, G. S., and Orlando, J. J.: A Product Yield Study of the Reaction of $\mathrm{HO}_{2}$ Radicals with Ethyl Peroxy $\left(\mathrm{C}_{2} \mathrm{H}_{5} \mathrm{O}_{2}\right)$, Acetyl Peroxy $\left(\mathrm{CH}_{3} \mathrm{C}(\mathrm{O}) \mathrm{O}_{2}\right)$, and Acetonyl Peroxy $\left(\mathrm{CH}_{3} \mathrm{C}(\mathrm{O}) \mathrm{CH}_{2} \mathrm{O}_{2}\right)$ Radicals, J. Phys. Chem. A, 108, 5979-5989, 2004.

Hastings, W. P., Koehler, C. A., Bailey, E. L., and De Haan, D. O.: Secondary organic aerosol formation by glyoxal hydration and oligomer formation: humidity effects and equilibrium shifts during analysis, Environ. Sci. Technol., 39, 8728-8735, 2005.

Heard, A. C., Pilling, M. J., and Tomlin, A. S.: Mechanism reduction techniques applied to tropospheric chemistry, Atmos. Environ., 32, 1059-1073, 1998.

Horowitz, L. W., Fiore, A. M., Milly, G. P., Cohen, R. C., Perring, A., Wooldridge, P. J., Hess, P. G., Emmons, L. K., and Lamarque, J.-F.: Observational constraints on the chemistry of isoprene nitrates over the eastern United States, J. Geophys. Res., 112, doi:10.1029/2006JD007747, 2007.

Houweling, S., Dentener, F., and Lelieveld, J.: The impact of nonmethane hydrocarbon compounds on tropospheric photochemistry, J. Geophys. Res., 103, D9, 10673-10696, 1998.

Jacob, D. J., Field, B. D., Li, Q., Blake, D. R., de Gouw, J., Warneke, C., Hansel, A., Wisthaler, A., Singh, H. B., and Guenther, A.: Global budget of methanol: Constraints from atmospheric observations, J. Geophys. Res., 110, doi:10.1029/ 2004JD005172, 2005.

Jenkin, M. E. and Hayman, G. D.: Kinetics of reactions of primary, secondary and tertiary $\beta$-hydroxy peroxyl radicals, J. Chem. Soc. Faraday Trans., 91, 1911-1922, 1995.

Jenkin, M. E., Saunders, S. M., and Pilling, M. J.: The tropospheric degradation of volatile organic compounds: A protocol for mechanism development, Atmos. Environ., 31, 81-104, 1997.

Jenkin, M. E., Boyd, A. A., and Lesclaux, R.: Peroxy radical kinetics resulting from the $\mathrm{OH}$-initiated oxidation of 1,3-butadiene, 2,3-dimethyl-1,3-butadiene and isoprene, J. Atmos. Chem., 29, 267-298, 1998.

Jenkin, M. E., Hurley, M. D. and Wallington, T. J.: Investigation of the radical product channel of the $\mathrm{CH}_{3} \mathrm{C}(\mathrm{O}) \mathrm{O}_{2}+\mathrm{HO}_{2}$ reaction in the gas phase, Phys. Chem. Chem. Phys., 9, doi: 10.1039/b702757e, 2007.

Jöckel, P., Tost, H., Pozzer, A., Brühl, C., Buchholz, J., Ganzeveld, L., Hoor, P., Kerkweg, A., Lawrence, M. G., Sander, R., Steil, B., Stiller, G., Tanarhte, M., Taraborrelli, D., van Ardenne, J., and Lelieveld, J.: The atmospheric chemistry general circulation model ECHAM5/MESSy1: consistent simulation of ozone from the surface to the mesosphere, Atmos. Chem. Phys., 6, 50675104, 2006, http://www.atmos-chem-phys.net/6/5067/2006/.

Kanakidou, M. and Crutzen, P. J.: The photochemical source of carbon monoxide: Importance, uncertainties and feedbacks, Chemosphere - Global Change Science, 1, 91-109, 1999.

Karl, M., Dorn, H.-P., Holland, F., Koppmann, R., Poppe, D., Rupp, L., Schaub, A., and Wahner, A.: Product study of the reaction of
$\mathrm{OH}$ radicals with isoprene in the atmosphere simulation chamber SAPHIR, J. Atmos. Chem., 55, 167-187, 2006.

Kroll, J. H., Ng, N. L., Murphy, S. M., Flagan, R. C., and Seinfeld, J. H.: Secondary organic aerosol formation from isoprene photooxidation, Environ. Sci. Technol., 40, 1869-1877, 2006.

Kubistin, D., Harder, H., Martinez, M., Rudolf, M., Sander, R., Bozem, H., Eerdekens, G., Fischer, H., Gurk, C., Klüpfel, T., Königstedt, R., Parchatka, U., Schiller, C. L., Stickler, A., Taraborrelli, D., Williams, J., and Lelieveld, J.: Hydroxyl radicals in the tropical troposphere over the Suriname rainforest: comparison of measurements with the box model MECCA, Atmos. Chem. Phys. Discuss., 8, 15239-15289, 2008, http://www.atmos-chem-phys-discuss.net/8/15239/2008/.

Kwok, E. S. C., Atkinson, R., and Arey, J.: Observation of hydroxycarbonyls from the $\mathrm{OH}$ radical-initiated reaction of isoprene, Environ. Sci. Technol., 29, 2467-2469, 1995.

Lathière, J., Hauglustaine, D. A., Friend, A. D., Noblet-Ducoudré, N. D., Viovy, N., and Folberth, G. A.: Impact of climate variability and land use changes on global biogenic volatile organic compound emissions, Atmos. Chem. Phys., 6, 2129-2146, 2006, http://www.atmos-chem-phys.net/6/2129/2006/.

Lawrence, M. G., Rasch, P. J., von Kuhlmann, R., Williams, J., Fischer, H., de Reus, M., Lelieveld, J., Crutzen, P. J., Schultz, M., Stier, P., Huntrieser, H., Heland, J., Stohl, A., Forster, C., Elbern, H., Jakobs, H., and Dickerson, R. R.: Global chemical weather forecasts for field campaign planning: predictions and observations of large-scale features during MINOS, CONTRACE, and INDOEX, Atmos. Chem. Phys., 3, 267-289, 2003, http://www.atmos-chem-phys.net/3/267/2003/.

Lee, W., Baasandorj, M., Stevens, P. S., and Hites, R. A.: Monitoring $\mathrm{OH}$-initiated oxidation kinetics of isoprene and its products using online mass spectrometry, Environ. Sci. Technol., 39, 1030-1036, doi:10.1021/es049438f, 2005.

Lelieveld, J., Butler, T. M., Dillon, T. J., Fischer, H., Ganzeveld, L., Harder, H., Lawrence, M. G., Martinez, M., Taraborrelli, D., and Williams, J.: Atmospheric oxidation capacity sustained by a tropical forest, Nature, 452, doi:10.1038/nature06870, 2008.

Lewin, A. G., Johnson, D., Price, D. W., and Marston, G.: Apects of the kinetics and mechanism of the gas-phase reaction of ozone with conjugated dienes, Phys. Chem. Chem. Phys., 3, 12531261, 2001.

Loeffler, K. W., Koehler, C. A., Paul, N. M., and De Haan, D. O.: Oligomer formation in evaporating glyoxal and methyl glyoxal solutions, Environ. Sci. Technol., 40, 6318-6323, 2006.

Madronich, S. and Calvert, J. G.: The NCAR Master Mechanism of Gas Phase Chemistry-Version 2.0, Technical note, NCAR, 1989.

Madronich, S. and Calvert, J. G.: Permutation reactions of organic peroxy radicals in the troposphere, J. Geophys. Res., 95D, 56975715, 1990.

Millet, D. B., Jacob, D. J., Custer, T. G., de Gouw, J. A., Goldstein, A. H., Karl, T., Singh, H. B., Sive, B. C., Talbot, R. W., Warneke, C., and Williams, J.: New constraints on terrestrial and oceanic sources of atmospheric methanol, Atmos. Chem. Phys., 8, 68876905, 2008, http://www.atmos-chem-phys.net/8/6887/2008/.

Miyoshi, A., Atakeyama, S., and Washida, N.: OH radical- initiated photooxidation of isoprene: An estimate of global CO production, J. Geophys. Res., 99, 18779-18787, 1994.

Müller, J.-F., Stavrakou, T., Wallens, S., Smedt, I. D., Roozendael, M. V., Potosnak, M. J., Rinne, J., Munger, B., Goldstein, A., 
and Guenther, A. B.: Global isoprene emissions estimated using MEGAN, ECMWF analyses and a detailed canopy environment model, Atmos. Chem. Phys., 8, 1329-1341, 2008, http://www.atmos-chem-phys.net/8/1329/2008/.

Myriokefalitakis, S., Vrekoussis, M., Tsigaridis, K., Wittrock, F., Richter, A., Brühl, C., Volkamer, R., Burrows, J. P., and Kanakidou, M.: The influence of natural and anthropogenic secondary sources on the glyoxal global distribution, Atmos. Chem. Phys., 8, 4965-4981, 2008,

http://www.atmos-chem-phys.net/8/4965/2008/.

Neeb, P. and Moortgat, G. K.: Formation of $\mathrm{OH}$ radicals in the gasphase reaction of propene, isobutene, and isoprene with $\mathrm{O}_{3}, \mathrm{~J}$. Phys. Chem. A, 103, 9003-9012, 1999.

Nenes, A., Charlson, R. J., Facchini, M. C., Kulmala, M., Laaksonen, A., and Seinfeld, J. H.: Can chemical effects on cloud droplet number rival the first indirect effect?, Geophys. Res. Lett., 29, doi:10.1029/2002GL015295, 2002.

Niki, H., Maker, P. D., Savage, C. M., Breitenbach, L. P., and Hurley, M. D.: FTIR spectroscopic study of the mechanism for the gas-phase reaction between ozone and tetramethylethylene, J. Phys. Chem., 91, 941-946, 1987.

Nizkorodov, S. A., Crounse, J. D., Fry, J. L., Roehl, C. M., and Wennberg, P. O.: Near-IR photodissociation of peroxy acetyl nitrate, Atmos. Chem. Phys., 5, 385-392, 2005,

http://www.atmos-chem-phys.net/5/385/2005/.

Orlando, J. J., Tyndall, G. S. and Paulson, S. E.: Mechanism of the $\mathrm{OH}$-initiated oxidation of methacrolein, Geophys. Res. Lett., 26, 2191-2194, 1999.

Patchen, A. K., Pennino, M. J., Kiep, A. C., and Elrod, M. J.: Direct kinetics study of the product-forming channels of the reaction of isoprene-derived hydroperoxy radicals with NO, Int. J. Chem. Kinetics, 39, 353-361, 2007.

Paulot, F., Crounse, J. D., Kjaergaard, H. G., Kroll, J. H., Seinfeld, J. H. and Wennberg, P. O.:, Isoprene photooxidation: new insights into the production of acids and organic nitrates, Atmos. Chem. Phys., 9, 1479-1501, 2009, http://www.atmos-chem-phys.net/9/1479/2009/.

Paulson, S. E., Flagan, R. C., and Seinfeld, J. H.: Atmospheric photooxidation of isoprene Part $\mathrm{I}$ : the $\mathrm{OH}$ and $\mathrm{O}(3 \mathrm{P})$ reactions, Int. J. Chem. Kinetics, 24, 79-101, 1992a.

Paulson, S. E., Flagan, R. C., and Seinfeld, J. H.: Atmospheric Photooxidation of isoprene Part II: The ozone-isoprene reaction, Int. J. Chem. Kinetics, 24, 103-125, 1992 b.

Paulson, S. E., Chung, M., Sen, A. D., and Orzechowska, G.: Measurement of $\mathrm{OH}$ radical formation from the reaction of ozone with several biogenic alkenes, J. Geophys. Res., 103, 2553325539, 1998.

Pfister, G. G., Emmons, L. K., Hess, P. G., Lamarque, J.-F., Orlando, J. J., Walters, S., Guenther, A., Palmer, P. I., and Lawrence, P. J.: Contribution of isoprene to chemical budgets: A model tracer study with the NCAR CTM MOZART-4, J. Geophys. Res., 113, doi:10.1029/2007JD008948, 2008.

Pinho, P. G., Pio, C. A., and Jenkin, M. E.: Evaluation of isoprene degradation in the detailed tropospheric chemical mechanism, MCM v3, using environmental chamber data, Atmos. Environ., 39, 1303-1322, 2005.

Pöschl, U., von Kuhlmann, R., Poisson, N., and Crutzen, P. J.: Development and intercomparison of condensed isoprene oxidation mechanisms for global atmospheric modeling, J. Atmos. Chem.,
37, 29-52, 2000.

Pozzer, A., Jöckel, P., Tost, H., Sander, R., Ganzeveld, L., Kerkweg, A., and Lelieveld, J.: Simulating organic species with the global atmospheric chemistry general circulation model ECHAM5/MESSy1: a comparison of model results with observations, Atmos. Chem. Phys., 7, 2527-2550, 2007, http://www.atmos-chem-phys.net/7/2527/2007/.

Rickard, A. R., Johnson, D., McGill, C. D., and Marston, G.: OH yields in the gas-phase reactions of ozone with alkenes, J. Phys. Chem. A, 103, 7656-7664, 1999.

Rohrer, F. and Berresheim, H.: Strong correlation between levels of tropospheric hydroxyl radicals and solar ultraviolet radiation, Nature, 442, doi:10.1038/nature04924, 2006.

Ruppert, L. and Becker, K. H.: A product study of the $\mathrm{OH}$ radicalinitiated oxidation of isoprene: formation of $\mathrm{C}_{5}$-unsaturated diols, Atmos. Environ., 34, 1529-1542, 2000.

Sander, R.: Compilation of Henrys Law Constants for Inorganic and Organic Species of Potential Importance in Environmental Chemistry, Tech. rep., Max-Planck Institute for Chemistry, 55020 Mainz, Germany, http://www.mpch-mainz.mpg.de/ 〜sander/res/henry.html, 1999.

Sander, R., Kerkweg, A., Jöckel, P., and Lelieveld, J.: Technical note: The new comprehensive atmospheric chemistry module MECCA, Atmos. Chem. Phys., 5, 445-450, 2005, http://www.atmos-chem-phys.net/5/445/2005/.

Sandu, A. and Sander, R.: Technical note: Simulating chemical systems in Fortran90 and Matlab with the Kinetic PreProcessor KPP-2.1, Atmos. Chem. Phys., 6, 187-195, 2006, http://www.atmos-chem-phys.net/6/187/2006/.

Sandu, A., Verwer, J. G., amd E. J. Spee, J. G. B., Carmichael, G. R., and Potra, F. A.: Benchmarking stiff ODE solvers for atmospheric chemistry problems II: Rosenbrock solvers, Atmos. Environ., 31, 3459-3472, 1997.

Sauer, F., Schafer, C., Neeb, P., Horie, O., and Moortgat, G. K.: Formation of hydrogen peroxide in the ozonolysis of isoprene and simple alkenes under humid conditions, Atmos. Environ., 33, 229-241, 1999.

Saunders, S. M., Jenkin, M. E., Derwent, R. G., and Pilling, M. J.: Protocol for the Development of the Master Chemical Mechanism, MCM v3 (Part A): tropospheric degradation of nonaromatic volatile organic compounds, Atmos. Chem. Phys., 3, 161-180, 2003, http://www.atmos-chem-phys.net/3/161/2003/.

Shepson, P., Mackay, E., and Muthuramu, K.: Henry's law constants and removal processes of several atmospheric $\beta$-hydroxy alkyl radicals, Environ. Sci. Technol., 30, 3618-3623, 1996.

Singh, H., Chen, Y., Staudt, A., Jacob, D., Blake, D., Heikes, B., and Snow, J.: Evidence from the Pacific troposphere for large global sources of oxygenated organic compounds, Nature, 410, doi:10.1038/35074067, 2001.

Sinreich, R., Volkamer, R., Filsinger, F., Frieß, U., Kern, C., Platt, U., Sebastian, O., and Wagner, T.: MAX-DOAS detection of glyoxal during ICARTT 2004, Atmos. Chem. Phys., 7, 1293-1303, 2007, http://www.atmos-chem-phys.net/7/1293/2007/.

Sprengnether, M., Demerjian, K. L., Donahue, N., and Anderson, J. G.: Product analysis of the $\mathrm{OH}$ oxidation of isoprene and 1,3butadiene in the presence of NO, J. Geophys. Res., 107, doi:10. 1029/2006JD007747, 2002.

Stockwell, W., Kirchner, F., Kuhn, M., and Seefeld, S.: A new mechanism for regional atmospheric chemistry modeling, 
Atmos. Environ., 102, 25847-25879, 1997.

Talukdar, R. K., Burkholder, J. B., Schmoltner, A.-M., Roberts, J. M., Wilson, R. R., and Ravishankara, A. R.: Investigation of the loss processes for peroxyacetyl nitrate in the atmosphere - UV photolysis and reaction with OH, J. Geophys. Res., 100, 14163-14173, 1995.

Torres, A. L. and Buchan, H.: Tropospheric nitric oxide measurements over the Amazon Basin, J. Geophys. Res., 93, 1396-1406, 1988.

Treves, K., Shragina, L., and Rudich, Y.: Henry's law constants of some $\beta$-, $\gamma$-, and $\delta$-hydroxy alkyl nitrates of atmospheric interest, Environ. Sci. Technol., 34, 1197-1203, 2000.

Tuazon, E. and Atkinson, R.: A product study of the gas-phase reaction of isoprene with the $\mathrm{OH}$ radical in the presence of $\mathrm{NO}_{\mathrm{x}}$, Int. J. Chem. Kinetics, 22, 1221-1236, 1990.

Volkamer, R., Molina, L. T., Molina, M. J., Shirley, T., and Brune, W. H.: DOAS measurement of glyoxal as an indicator for fast VOC chemistry in urban air, Geophys. Res. Lett., 32, doi:10.1029/2005GL022616, 2005.

Volkamer, R., Martini, F. S., Molina, L. T., Salcedo, D., Jimenez, J. L., and Molina, M. J.: A missing sink for gas-phase glyoxal in Mexico City: Formation of secondary organic aerosol, Geophys. Res. Lett., 34, doi:10.1029/2007GL030752, 2007.

von Kuhlmann, R., Lawrence, M. G., Crutzen, P. J., and Rasch, P. J.: A model for studies of tropospheric ozone and nonmethane hydrocarbons: Model evaluation of ozone-related species, J. Geophys. Res., 108, doi:10.1029/2002JD003348, 2003.

von Kuhlmann, R., Lawrence, M. G., Pöschl, U., and Crutzen, P. J.: Sensitivities in global scale modeling of isoprene, Atmos. Chem. Phys., 4, 1-17, 2004, http://www.atmos-chem-phys.net/4/1/2004/.

Yokouchi, Y.: Seasonal and diurnal variation of isoprene and its reaction products in a semi-rural area, Atmos. Environ., 28, 26512658, 1994.
Wang, K. Y. and Shallcross, D. E.: Modelling terrestrial biogenic isoprene fluxes and their potential impact on global chemical species using a coupled LSM-CTM model, Atmos. Environ., 34, 2909-2925, 2000.

Wang, Y., Jacob, D. J., and Logan, J. A.: Global simulation of tropospheric $\mathrm{O}_{3}-\mathrm{NO}_{\mathrm{x}}$-hydrocarbon chemistry 1 . Model formulation, J. Geophys. Res., 103, 10713-10725, 1998.

Warneke, C., Holzinger, R., Hansel, A., Jordan, A., Lindinger, W., Pöschl, U., Williams, J., Hoor, P., Fischer, H., Crutzen, P. J., Scheeren, H. A., and Lelieveld, J.: Isoprene and its oxidation products methyl vinyl ketone, methacrolein, and isoprene related peroxides measured online over the tropical rain forest of Surinam in March 1998, J. Atmos. Chem., 38, 167-185, 2001.

Whitehouse, L. E., Tomlin, A. S., and Pilling, M. J.: Systematic reduction of complex tropospheric chemical mechanisms, Part I: sensitivity and time-scale analyses, Atmos. Chem. Phys., 4, 2025-2056, 2004, http://www.atmos-chem-phys.net/4/2025/2004/.

Whitehouse, L. E., Tomlin, A. S., and Pilling, M. J.: Systematic reduction of complex tropospheric chemical mechanisms, Part II: Lumping using a time-scale based approach, Atmos. Chem. Phys., 4, 2057-2081, 2004, http://www.atmos-chem-phys.net/4/2057/2004/.

Williams, J., Pöschl, U., Crutzen, P. J., Hansel, A., Holzinger, R., Warneke, C., Lindinger, W., and Lelieveld, J.: An Atmospheric Chemistry Interpretation of Mass Scans Obtained from a Proton Transfer Mass Spectrometer Flown over the Tropical Rainforest of Surinam, J. Atmos. Chem., 38, 133-166, 2001.

Wittrock, F., Richter, A., Oetjen, H., Burrows, J. P., Kanakidou, M., Myriokefalitakis, S., Volkamer, R., Beirle, S., Platt, U., and Wagner, T.: Simultaneous global observations of glyoxal and formaldehyde from space, Geophys. Res. Lett., 33, doi: 10.1029/2006GL026310, 2006. 